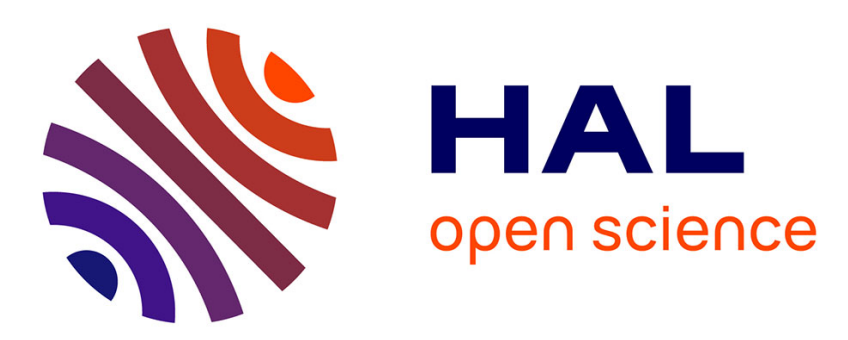

\title{
Comparison of model predictive control strategies for the simulated moving bed
}

\author{
Adrian Dietz, Jean Pierre Corriou
}

\section{To cite this version:}

Adrian Dietz, Jean Pierre Corriou. Comparison of model predictive control strategies for the simulated moving bed. Computer Aided Chemical Engineering, 2008, 10.1016/S1570-7946(08)80060-0 . hal02383573

\section{HAL Id: hal-02383573 \\ https://hal.science/hal-02383573}

Submitted on 27 Nov 2019

HAL is a multi-disciplinary open access archive for the deposit and dissemination of scientific research documents, whether they are published or not. The documents may come from teaching and research institutions in France or abroad, or from public or private research centers.
L'archive ouverte pluridisciplinaire HAL, est destinée au dépôt et à la diffusion de documents scientifiques de niveau recherche, publiés ou non, émanant des établissements d'enseignement et de recherche français ou étrangers, des laboratoires publics ou privés. 


\title{
Comparison of model predictive control strategies for the simulated moving bed
}

\author{
Adrian Dietz, Jean-Pierre Corriou ${ }^{a *}$ \\ ${ }^{a}$ LSGC, Nancy Université, CNRS, BP20451 F-54001 Nancy Cedex France
}

\begin{abstract}
This work compares three ways of controlling the simulated moving bed (SMB), an efficient process for chromatographic separation. Linear model predictive control (MPC) is considered in this work. A comparison of two different sets of manipulated inputs is carried out: on one hand, the classical one often presented in the literature, which consists in manipulating directly different flow rates involved in the process and, on the other hand, an approach coming from other counter-current separation processes which consists in manipulating the ratios of flow rates of each SMB zone. A hybrid method using the inputs calculated for a true moving bed (TMB) and implemented on the SMB is also compared. The advantages and drawbacks of each control strategy are discussed. In all cases, results show clearly the interest of applying MPC to high complexity systems such as the SMB.
\end{abstract}

Keywords: simulated moving bed, model predictive control.

\section{Introduction}

Chromatographic techniques allow the separation of products with a high purity required in industrial fields such as fine chemistry, pharmaceutics, food. The chromatographic operation is usually operated in batch mode and is well known for its high investment cost due to the adsorbent and large eluent consumption. In order to tackle this drawback, the continuous moving bed technology was first studied

*corriou@ensic.inpl-nancy.fr, to whom correspondence should be sent 
as the true moving bed (TMB) (Figure 1) where the solid and the liquid flows move in countercurrent way. However, because of the solid flow, this process causes solid attrition, so that the SMB technology was introduced for real practice. In a SMB, the solid movement is simulated by simultaneous switching of the inlet and exit ports corresponding to feed, eluent, extract and raffinate, in direction of the fluid flow (Figure 2). Consequently, the continuous system corresponding to the TMB where a steady state can be obtained is transformed into a hybrid system resulting from the cyclic operation mode. Typical studies in the literature range from the design stage [Charton and Nicoud, 1995, Ching et al., 1992, Nicoud, 1992] to the operation [Mazzotti et al., 1998], identification [Song et al., 2006], parameter and state estimation [Alamir and Corriou, 2003, Corriou and Alamir, 2006, Kloppenburg and Gilles, 1999], and control [Alamir et al., 2006, Erdem et al., 2004, Klatt et al., 2002, Natarajan and Lee, 2000, Thabet et al., 1997, Toumi and Engell, 2004] of the SMB. Many different control techniques are mentioned including linear and non linear model predictive control and non linear geometric control. Several variants of this technology are also developed such as the Varicol [Song et al., 2006, Toumi et al., 2003, Zhang et al., 2003a] process or the power feed operation [Zhang et al., 2003b].

In this work, two different model predictive control strategies of a SMB differing by the choice of the manipulated inputs are compared. On one hand, the classical one often presented in the literature consists in directly manipulating different flow rates involved in the process and, on the other hand, the strategy mentioned by [Couenne et al., 2002] consists in manipulating ratios of flow rates and is used for xylenes separation. The idea of choosing ratios of flow rates as manipulated inputs was already used in distillation control [Skogestad et al., 1990] where Skogestad considers the two-ratio configuration $(L / D, V / B)$ as the best choice in case of dual control. In the same manner, the choice of flow rates ratios seems to be interesting for the SMB control because it is assumed to reduce the high non-linearity of the process as the separation phenomena are directly related to ratios of flow rates rather than to flow rates themselves. In the control scheme by ratios of flow rates [Couenne et al., 2002] of the SMB, the two main outputs are the purity and yield of the products, two other outputs are respectively defined to guarantee a stable operation of the process and to optimize it. The manipulated inputs are the ratios of liquid flow rate in zone $k$ divided by the equivalent solid flow rate $\left(Q_{k} / Q_{\text {sol }}\right)$. In the control scheme by 
flow rates, the controlled outputs are the purities at the extract $P_{\text {ext }}$ and raffinate $P_{\text {raf }}$ outlets defined as

$$
P_{e x t}=\frac{\int_{0}^{t_{s w}} Q_{e x t} C_{B, e x t} d t}{\int_{0}^{t_{s w}} Q_{e x t} C_{A, e x t} d t+\int_{0}^{t_{s w}} Q_{e x t} C_{B, e x t} d t} ; P_{r a f}=\frac{\int_{0}^{t_{s w}} Q_{r a f} C_{A, r a f} d t}{\int_{0}^{t_{s w}} Q_{r a f} C_{A, r a f} d t+\int_{0}^{t_{s w}} Q_{r a f} C_{B, \text { raf }} d t}
$$

where $t_{s w}$ is the switching period between two successive switching instants. Note that these purities refer to the interesting components in each stream. The manipulated inputs are the eluent (solvent) $Q_{e l u}$, extract $Q_{e x t}$, recycle $Q_{r e c}$ and equivalent solid $Q_{\text {sol }}$ flow rates. Another type of control used for comparison, noted as hybrid control, consists in first calculating the manipulated inputs by means of the model of the TMB, then implementing them on the actual SMB. The different types of control considered in this study differing by the type of manipulated inputs are summarized in Table 1.

Table 1: Definition of control strategies ( $Q$ means flow rate, $P$ means purity)

\begin{tabular}{|l|l|l|l|}
\hline & $\begin{array}{l}\text { Control by } \\
\text { flow rates } \\
\text { Denomination }\end{array}$ & $\begin{array}{l}\text { Control by } \\
\text { ratios of flow rates } \\
\text { (Flow rate Control) }\end{array}$ & $\begin{array}{l}\text { Control by } \\
\text { flow rates of TMB on SMB } \\
\text { (Hybrid control) }\end{array}$ \\
\hline Manipulated input & & & \\
\hline$u_{1}$ & $Q_{\text {Solvent }}$ & $Q_{I} / Q_{\text {EquivalentSolid }}$ & $Q_{\text {Solvent }, T M B}$ \\
$u_{2}$ & $Q_{\text {Extract }}$ & $Q_{I I} / Q_{\text {EquivalentSolid }}$ & $Q_{\text {Extract }, T M B}$ \\
$u_{3}$ & $Q_{\text {Recycle }}$ & $Q_{I I I} / Q_{\text {EquivalentSolid }}$ & $Q_{\text {Recycle,TMB }}$ \\
$u_{4}$ & $Q_{\text {EquivalentSolid }}$ & $Q_{I V} / Q_{\text {EquivalentSolid }}$ & $Q_{\text {Solid,TMB }}$ \\
\hline Controlled outputs $y$ & \multicolumn{2}{|c|}{$P_{\text {ext }}$ and $P_{\text {raf }}$} \\
\hline
\end{tabular}

A linear model predictive control law [Garcia and Morshedi, 1986] is retained in all cases because of its attracting characteristics such as its multivariable aspects and the possibility of taking into account "hard" constraints on inputs and input variations as well as "soft" constraints on outputs (constraint violation is authorized during a short period of time). To practice model predictive control, first a linear model of the process must be obtained off-line before applying the optimization strategy to calculate on-line the manipulated inputs. 


\section{Model of the process}

A typical SMB is divided in four zones (Figure 2), each zone includes two columns. The model of the SMB is described in [Corriou and Alamir, 2006] with its parameters. It is based on the partial differential equation for the mass balance, a mass transfer equation between the liquid and the solid phase, and an equilibrium law. In the present case, a nonlinear Langmuir isotherm describes the binary equilibrium for each component between the adsorbent and the liquid phase. For simulation purposes, the PDE equation is discretized as an equivalent system of mixers in series [Alamir and Corriou, 2003, Alamir et al., 2006]. Each column is composed of twenty mixers.

\subsection{True moving bed}

The model of the TMB which is used in the hybrid control is first presented. The difference with the SMB resides in the effective movement of the solid phase.

The global mass balance equation in a section $j$ for a component $i$ is

$$
\epsilon \frac{\partial C_{j}^{i}}{\partial t}+(1-\epsilon) \frac{\partial q_{j}^{i}}{\partial t}+\epsilon v_{j} \frac{\partial C_{j}^{i}}{\partial z}-\epsilon \mathcal{D} \frac{\partial^{2} C_{j}^{i}}{\partial z^{2}}-(1-\epsilon) v_{s} \frac{\partial q_{j}^{i}}{\partial z}=0
$$

where $v_{j}$ is the liquid velocity in section $j$ (related to the flow rate $F_{j}$ by the relation $F_{j}=\epsilon \Omega u_{j}$ ), $\Omega$ cross section of a column, $\epsilon$ porosity, $\mathcal{D}$ axial dispersion coefficient. This relation must be completed by the mass balance equation in the porous phase

$$
\frac{\partial q_{j}^{i}}{\partial t}-v_{s} \frac{\partial q_{j}^{i}}{\partial z}=k_{i}\left(q_{j}^{i *}-q_{j}^{i}\right)
$$

where $q_{j}^{i *}$ is the concentration of adsorbed component $i$ which would be in equilibrium with component $i$ in the liquid phase, $v_{s}$ solid velocity, $k_{i}$ mass transfer coefficient.

The non linear equilibrium law retained in this work is the Langmuir one given by

$$
q^{i}=\frac{q^{m i} K^{i} C^{i}}{1+\sum_{i=1}^{n_{c}} K^{i} C^{i}}
$$

where $n_{c}$ is the number of components.

Boundary conditions complete the model between the different sections. 


\subsection{Simulated moving bed}

The global mass balance equation in a section $j$ for a component $i$ is modified with respect to the TMB as

$$
\epsilon \frac{\partial C_{j}^{i}}{\partial t}+(1-\epsilon) \frac{\partial q_{j}^{i}}{\partial t}+\epsilon v_{j} \frac{\partial C_{j}^{i}}{\partial z}-\epsilon \mathcal{D} \frac{\partial^{2} C_{j}^{i}}{\partial z^{2}}=0
$$

It must be noted that, with regard to equation (2), the term related to the solid velocity $v_{s}$ has disappeared.

The mass balance equation on the porous phase (3) is modified as the solid velocity is zero

$$
\frac{\partial q_{j}^{i}}{\partial t}=k_{i}\left(q_{j}^{i *}-q_{j}^{i}\right)
$$

The equilibrium equation of Langmuir type (4) is retained as it is independent on the type of moving bed.

\section{Case Study}

The system modeled in this work is a SMB containing two columns by section giving a total number of eight identical columns. When the TMB is mentioned, it contains the same number of columns and has identical properties. The TMB and SMB characteristics are given in Table 2. The feed is a binary mixture of two products A and B to separate, A being the product mostly recovered in the raffinate and B the product recovered in the extract. The separation is not considered as difficult, however its characteristics are sufficiently interesting to facilitate the comparison between the three modes of control that will be tested.

The operating conditions were selected in order to obtain a purity of $95 \%$ for both products at the extract and the raffinate respectively. The operating conditions implemented in order to obtain this purity at the steady state conditions are presented in Table 3 and 4 for the TMB and the SMB respectively. It must be noted that in the case of the TMB, the solid flow rate exists really whereas it is replaced by an equivalent flow rate for the SMB. The equivalence between the switching period $T_{s w}$ and the solid flow rate $Q_{\text {sol }}$ is given by

$$
T_{s w}=\frac{(1-\epsilon) V_{c}}{Q_{s o l}}
$$

where $\epsilon$ is the column porosity and $V_{c}$ is the volume of one column. It must be noted that other flow rate combinations can lead to the same product purity. 
Table 2: TMB and SMB common characteristics

\begin{tabular}{|l|l|}
\hline Number of sections & 4 \\
Columns by section & 2 \\
Column height $(\mathrm{cm})$ & 50 \\
Feed flow rate $\left(\mathrm{cm}^{3} / \mathrm{s}\right)$ & 5 \\
Feed concentration $(\mathrm{A}$ and $\mathrm{B})\left(\mathrm{g} / \mathrm{cm}^{3}\right)$ & 0.0005 \\
Langmuir constant $K_{1}, K_{2}$ & 1000,2000 \\
Langmuir constant $q_{m 1}=q_{m 2}$ & 0.005 \\
\hline
\end{tabular}

Table 3: TMB operating conditions

\begin{tabular}{|l|l|}
\hline Flow rate & Value in $\left(\mathrm{cm}^{3} / \mathrm{s}\right)$ \\
\hline Solvent flow rate & 106.685 \\
Extract flow rate & 67.6314 \\
Recycle flow rate & 122.541 \\
Solid flow rate & 24.3109 \\
\hline
\end{tabular}

\section{Steady State Simulation Results}

First, simulations are carried out in order to validate the selected operating conditions. Figure 3 shows the concentration profile at the steady state condition for the raffinate product B in the case of the SMB process. As mentioned previously, in a SMB, only a cyclic steady state can be obtained after a large simulation time. The aim is to keep the raffinate valve open while the concentration of the product of interest is high and then operate the switching when it decreases.

In order to validate the interest of using the ratios of flow rates as manipulated inputs rather than the flow rates themselves, different simulations are carried out.

First, the hypothesis of linear behaviour of the process is tested. A typical linear process would yield step responses $\delta y=y(t)-y_{s s}$ which are proportional to the magnitude of the input variation $\delta u=u(t)-u_{s s}$ and possess a time constant independent of the magnitude of the input. $u_{s s}$ and $y_{s s}$ are 
Table 4: SMB operating conditions

\begin{tabular}{|l|l|}
\hline Flow rate & Value in $\left(\mathrm{cm}^{3} / \mathrm{s}\right)$ \\
\hline Solvent flow rate & 106.495 \\
Extract flow rate & 62.7368 \\
Recycle flow rate & 106.99 \\
Equivalent solid flow rate & 23.0686 \\
\hline
\end{tabular}

respectively the input and output value at steady state. On the contrary, a non linear process would not possess at least one of these two characteristics. To show the possible influence of the magnitude of the input, the step response can be normalized by the input variation $\delta u$. Furthermore, the asymptotic gain given as

$$
K_{\infty}=\frac{\delta y_{\infty}}{\delta u_{\infty}}
$$

i.e. the asymptotic output variation normalized by the step input variation can be calculated. For a linear process, this gain $K_{\infty}$ should be independent on the step magnitude of the input, this latter being represented in the following by the relative amplitude of the step $\delta u_{\infty} / u_{s s}$.

First, the classical control approach of the SMB where the manipulated inputs are the flow rates is considered. The input and output values at steady state are given in Tables 3 and 4 . The manipulated inputs are the flow rates given in Table 1. For illustration purposes, only the asymptotic gain of the responses to the relative variation of the eluent flow rate is shown (Figure 4). It is clear that the gain is not constant, especially with regard to the raffinate purity. Thus, around the steady state, the asymptotic gain can be approximately fitted (Figure 4) with respect the relative input variation by a linear regression of the form

$$
K_{\infty}=a+b \frac{\delta u_{\infty}}{u_{s s}}
$$

however without any justification related to the equations or behaviour of the process. For a purely linear process, $b$ would be equal to $0, K_{\infty}$ would be reduced to $a$, and thus $b$ represents the extent of non linearity of the system. The values of $a$ and $b$ are presented in Table 5. The main non linearity is related to the solid flow rate and the lower one to the extract flow rate.

In a second stage, the case where the ratios of the flow rate are used is considered. In Figure 5, 
Table 5: Values of $a$ and $b$ in equation (9)

\begin{tabular}{|l|l|l|l|l|}
\hline \multirow{2}{*}{ Flow rate } & \multicolumn{2}{|c|}{ a } & \multicolumn{2}{c|}{ b } \\
\cline { 2 - 5 } & Extract Purity & Raffinate Purity & Extract Purity & Raffinate Purity \\
\hline Eluent & 0.0028 & 0.0075 & -0.0040 & -0.0332 \\
Extract & 0.0006 & -0.0078 & -0.0007 & -0.0216 \\
Recycle & 0.0032 & 0.0076 & -0.0068 & -0.0347 \\
Solid & -0.0295 & -0.0539 & -0.1020 & -0.3600 \\
\hline
\end{tabular}

the asymptotic gain $\left(\delta y_{\infty} / \delta u_{\infty}\right)$ is presented with respect to the relative step variation of the flow rate ratio in section I. It can be seen that this asymptotic normalized output variation or the asymptotic gain is little dependent on $\delta u$, so that it can be considered that the output variations have a nearly linear behavior with respect to the selected manipulated inputs. It must be noted that the relative input variation is considerably lower in the case of ratios of flow rates because the system is highly sensitive to these parameters and the SMB can be easily displaced out of the normal working conditions (i .e. the solid cannot be regenerated). These results show the interest of considering the ratios of the flow rates as manipulated inputs because, as expected, they reduce the high non-linearity of the studied system.

This approximately linear behavior of the process observed for input 1 in Figure 5 was verified for the whole set of responses. This can be expressed by equation (9), where $K_{\infty}$ can be regarded as the sensitivity of the process to the manipulated inputs. These values are presented in Table 6 . With respect to (9), it corresponds to $a=K_{\infty}$ and $b=0$. As it will be expected, corresponding to larger values of $K_{\infty}$, the system is more sensitive to the flow rate in sections II and III where the effective product separation is carried out.

\section{Identification of the linear model}

Model predictive control being used as a linear control strategy, step responses of the process with respect to the various manipulated inputs represent the linear model of the process. As mentioned previously, in a SMB, the solid flow is simulated by synchronous valve switching at given intervals. The switching period of the SMB is computed from the equivalent solid flow rate by means of (7). A variable switching 
Table 6: Output sensitivity $K_{\infty}$ to input variations

\begin{tabular}{|l|l|l|}
\hline Flow rate & Extract Purity & Raffinate Purity \\
\hline Section I & 0.0818 & -0.0080 \\
Section II & -0.1149 & -0.5167 \\
Section III & 0.0972 & 0.7327 \\
Section IV & 0.0078 & 0.0016 \\
\hline
\end{tabular}

period induces a varying sampling period as the measurements are assumed to be performed only after each commutation and correspond to average concentrations over this switching period.

\subsection{Linear model for flow rate control}

The step responses of the extract and raffinate purities (Figure 6) are obtained for $0.05 \%$ steps of respective eluent, recycle, extract and solid flow rates used as manipulated inputs. The steps are performed after the process reaches a steady state purity of $95 \%$ for both products. In Figure 6, they are represented as normalized step responses, i.e. $\delta y_{j} / \delta u_{i}$, where $\delta u_{i}$ is the variation of $i^{\text {th }}$ manipulated input with respect to a steady state value and $\delta y_{j}$ is the variation of $j^{\text {th }}$ controlled variable with respect to the corresponding steady state value. Most of the responses are close to first order step responses and present similar time constants, which is suitable for further control. Only the step response of the extract purity with respect to the eluent flow rate $\left(\delta y_{1} / \delta u_{2}\right)$ displays an inverse response, however it has a low order of magnitude like two other step responses $\left(\delta y_{1} / \delta u_{1}, \delta y_{1} / \delta u_{3}\right)$.

\subsection{Linear model for ratio control}

The step responses for ratio control are obtained by varying successively the ratios of the liquid flow rates of the successive zones over the equivalent solid flow rate (Figure 7). The liquid flow rates are calculated from the ratios in order to obtain a constant flow rate ratio in each zone of the SMB. The results show that several inverse responses are present, moreover different types of response dynamics exist.

The ratio step responses are very different from the simple flow rate step responses of Figure 6. Second order responses are present $\left(\delta y_{1} / \delta u_{2}, \delta y_{1} / \delta u_{3}\right)$, some step responses show low magnitudes $\left(\delta y_{1} / \delta u_{4}, \delta y_{2} / \delta u_{1}, \delta y_{2} / \delta u_{4}\right)$. Also, time constants are relatively different, with essentially smaller 
time constants associated to low gains (visible in $\delta y_{1} / \delta u_{4}$ and slightly in $\delta y_{2} / \delta u_{1}$ and $\delta y_{2} / \delta u_{2}$ before $t \approx 200 \mathrm{~s}$ ), and larger time constants associated to larger gains (such as for $\delta y_{1} / \delta u_{1}$ ). From these facts some difficulties can be expected when using this information for the SMB control. It must be noted that the SMB presents natural delays due to the distributed character of the process, and which are consequently unavoidable. The switching period is depending on the equivalent solid flow rate, furthermore the sampling period is equal to the switching period. Consequently, when different $\delta u_{i}$ are considered, they correspond to different sampling periods and the time corresponding to a given model horizon expressed as an integer value will be different according to the type of input considered (Figure 6). This does not cause any problem because for all the cases the system dynamics is well represented and for the later control law application a cubic splines interpolation is carried out to estimate the coefficients of the dynamic matrix of the process.

\subsection{Hybrid approach}

The hybrid approach can be simply resumed: the step responses obtained by means of the model of the TMB are used to construct the dynamic matrix of the process which is later used for the control of the SMB. Figure 8 presents the responses of the TMB to flow rate variations. The responses of the TMB and the SMB submitted to flow rate variations are very similar because both models are equivalent for a high number of columns by section. The main advantage is that in this case the sampling time can be imposed by the user and is not obtained as the switching period time.

\section{Model predictive control}

The model predictive control used in this study is formulated as a quadratic programming problem mainly under the form of Quadratic Dynamic Matrix Control (QDMC) [Corriou, 2004, Garcia and Morshedi, 1986]. It thus deals with the minimization of the following quadratic criterion

$$
\min _{\Delta \boldsymbol{u}(k)}\left[\frac{1}{2} \Delta \boldsymbol{u}(k)^{T} \boldsymbol{H} \Delta \boldsymbol{u}(k)-\boldsymbol{g}(k+1)^{T} \Delta \boldsymbol{u}(k)\right]
$$

subject to linear hard constraints for the inputs

$$
\boldsymbol{u}_{\min } \leq \boldsymbol{u} \leq \boldsymbol{u}_{\max }
$$


and the variations of the inputs

$$
\boldsymbol{B} \Delta \boldsymbol{u}(k) \leq \boldsymbol{c}(k+1)
$$

$\boldsymbol{H}$ is the Hessian matrix (in general fixed) equal to

$$
\boldsymbol{H}=\mathcal{A}^{T} \boldsymbol{\Gamma}^{T} \boldsymbol{\Gamma} \mathcal{A}+\boldsymbol{\Lambda}^{T} \boldsymbol{\Lambda}
$$

and $\boldsymbol{g}(k+1)$ is the gradient vector equal to

$$
\boldsymbol{g}(k+1)=\mathcal{A}^{T} \boldsymbol{\Gamma}^{T} \boldsymbol{\Gamma} \boldsymbol{e}(k+1)
$$

where $\boldsymbol{e}(k+1)$ is the error given by

$$
\boldsymbol{e}(k+1)=\left[\begin{array}{l}
e(k+1) \\
\vdots \\
e\left(k+H_{p}\right)
\end{array}\right]=\left[\begin{array}{l}
y^{r e f}(k+1) \\
\vdots \\
y^{r e f}\left(k+H_{p}\right)
\end{array}\right]-\left[\begin{array}{l}
y^{*}(k+1 \mid k) \\
\vdots \\
y^{*}\left(k+H_{p} \mid k\right)
\end{array}\right]-\left[\begin{array}{l}
\hat{d}(k \mid k) \\
\vdots \\
\hat{d}\left(k+H_{p} \mid k\right)
\end{array}\right]
$$

with $y^{r e f}(k+i)$ the reference trajectory, $y^{*}(k+i \mid k)$ the output prediction based on past input variations, $\hat{d}(k+i \mid k)$ the estimated disturbance considered as constant and equal to $d(k)=y(k)-y^{*}(k \mid k)$. $\mathcal{A}$ is the dynamic matrix based on the step response coefficients previously determined in the system identification. $\boldsymbol{\Gamma}$ and $\boldsymbol{\Lambda}$ are weight matrices for performance and energy respectively. In general, the weight matrices are chosen diagonal. However, the QDMC control has been improved to take into account soft output constraints by addition of a penalty function in the criterion. It then becomes a non linear optimization problem which is solved numerically by the NLPQL subroutine [Schittkowski, 1985]. A set of C++ classes was developed to implement Model Predictive Control, C and Fortran 77 libraries are used for both numerical integration and optimization. Practically, the manipulated inputs calculated by any predictive control are imposed to the full nonlinear model of the SMB which represents the plant. The objective of the control simulations is to study the tracking of both purities and the influence of disturbances of feed flow rate or feed composition.

In the following, the closed loop results obtained for the three techniques are presented. Each figure contains on the left side the system output and setpoint, the upper correspond to the raffinate and the lower to the extracts, and on the right side the manipulated inputs, eluent, extract, recycle and solid flow rates respectively. Several points must be emphasized before discussing the results obtained. Being given that the sampling period depends on the solid flow rate, the dynamic matrix must be rebuilt at each 
computing step. In order to maintain the QL (optimization of quadratic criterion with linear constraints) nature of the optimization problem in absence of soft output constraints, the switching period for the future inputs is assumed to be identical to the first one calculated. Even though the results presented here use a unitary control horizon, no significant improvements are observed when using a larger value. Moreover, it often creates some extra difficulties for the ratio control. For the tracking study, a set point change of the raffinate and extract purity from 0.95 to 0.96 and back to 0.95 is carried out, the control of the raffinate purity is well ensured and the manipulated inputs undergo acceptable moves. The disturbance rejection is studied with respect to two different disturbances, either a feed flow rate disturbance or a feed concentration disturbance, both of $+10 \%$ and $-10 \%$ at times 13000 s and 19000 s.

\subsection{Control by flow rates}

When the selected manipulated inputs are the flow rates, the results are presented in Figures 9 to 13. It can be observed that the raffinate and extract purities are very well tracked (Figure 9 and Figure 10). The error between the setpoint and process outputs remains slight, and this is obtained with smooth moves on the manipulated inputs. The influence of disturbances is presented in three studies where Figure 11 concerns a flow rate disturbance, Figure 12 and Figure 13 refer respectively to the disturbances with respect to the main product in the raffinate and in the extract. In all cases, the disturbances are well rejected. The manipulated flow rates are stabilized after a transient period which last about about 1000s. The raffinate purity is more affected by the disturbance than the extract purity.

\subsection{Control by ratios of flow rates}

Ratio control deals with the case where the manipulated inputs are the ratios of the liquid flow rates in each zone over the equivalent solid flow rate. Even though the manipulated inputs are the ratios, the operating flow rates are shown in the Figures instead of the manipulated inputs, because they correspond to the physical operating conditions and allow us to carry out a comparison with the other control strategies. The tracking results (Figures 14 and 15) display a much larger error than in case of flow rate control. Oscillations are present in particular in the extract purity and the manipulated inputs moves are less smooth with often pronounced oscillations. Concerning the disturbances rejection, the results are totally different according to whether they deal with feed flow rate or feed concentration. Consider first the feed flow rate disturbance. As the process separation depends on the flow rate ratios, these latter 
being the manipulated variables, no changes in the ratios are necessary for keeping the same production purity (Figure 16). Note that the use of this technique is possible only if the feed flow rate is measured. It can be concluded that the ratio control technique takes advantage of the information on the feed flow rate if it is available, otherwise if the feed flow rate is unmeasured and constitutes an unknown disturbance, it is applicable only if an unknown input observer is developed. With regard to feed flow concentration disturbances (Figures 17 and 18), the results show larger deviations and sustained oscillations compared to the other strategies.

\subsection{Hybrid control}

Recall that hybrid control consists in carrying out the identification based on the TMB model and then using the responses for the dynamic matrix of the MPC control of the SMB. This method has the advantage of getting the information from a single continuous model. The tracking (Figures 19 and 20) show results extremely close to flow rate control of the SMB, with a much better performance than ratio control. The feed flow rate disturbance is again rejected (Figure 21) in a very similar way to the case of flow rate control. The feed concentration disturbances (Figures 22 and 23) are also rejected very closely to the case of flow rate control. In summary, the difference between results for set point tracking and disturbance rejection in cases of flow rate control and hybrid control is nearly undistinguishable even if the dynamic matrix used the information of the responses by means of a model different from the actual process. This procedure can be advantageous as the model of the TMB is available under a continuous form.

\subsection{Comparison between the three control approaches}

Globally, the classical strategy of flow rate control implemented in the model predictive control framework gives satisfactory results even if the feed flow rate is considered as an unmeasured disturbance and its rejection is less efficient than for the ratio control. In this latter, the feed flow rate must be measured and its disturbance is rejected without dynamic effects as the manipulated inputs are algebraically and linearly related to the disturbance value. On the other side, concerning set point tracking and feed concentration disturbances, the performances of ratio control are considerably worse than those of the two other controls control. The capacity of ratio control to reject feed flow rate disturbances remains attractive in some particular cases such as the pharmaceutical or the fine chemistry where the production 
is carried out by batches. In these cases, in general, the set point is maintained constant because it is associated to the batch recipe resulting in a given final product concentration, and the main disturbance comes from the feed flow rate that can be modified by the pump operation or the operator. The hybrid control based on the simulation model of the TMB to construct the dynamic matrix of MPC shows good quality performances extremely close to those of flow rate control. For identification, the hybrid strategy lies on the continuous model of the TMB instead of the continuous-discrete model of the SMB which makes it simpler to use for further control. Furthermore, its closed loop properties very similar to flow rate control make flow rate control appealing to validate any control law in simulation.

\section{Conclusions and Perspectives}

The influences of two different sets of manipulated inputs have been compared in the case of linear model predictive control of a simulated moving bed. The first one consisting in direct manipulation of flow rates of the SMB showed a very satisfactory behavior for set point tracking and feed disturbance rejection. The second one consists in manipulating the flow rates ratios over each SMB section. At the identification stage, this strategy proved to be more delicate as the step responses displayed important dynamic differences of the responses. However, when the disturbance concerns the feed flow rate, a perfect behavior is obtained whereas the set point tracking performance is not satisfactory and the feed concentration disturbances are more badly rejected. A third strategy, called hybrid control, based on the continuous model of the TMB for identification of the dynamic matrix, showed all performances very close to flow rate control and render it very attractive for MPC control of the SMB. Other control studies, such as robustness and tests of control strategies, will be carried out in next works. Although the SMB control was carried out in simulation based on a realistic model of the process, the application of these control strategies to a real SMB for validation purposes remains to be done.

\section{References}

M. Alamir and J. P. Corriou. Nonlinear receding horizon state estimation for dispersive adsorption columns with nonlinear isotherm. Journal of Process Control, 13(6):517-523, 2003.

M. Alamir, F. Ibrahim, and J. P. Corriou. A flexible nonlinear model predictive control scheme for quality 
/ performance handling in nonlinear smb chromatography. Journal of Process Control, 16:333-344, 2006.

F. Charton and R. M. Nicoud. Complete design of a simulated moving bed. J. Chromatogr. A, 702: $97-112,1995$.

C. B. Ching, K. H. Chu, K. Hidajat, and M. S. Uddin. Comparative study of flow schemes for a simulated counter-current adsorption separation process. AIChE J., 38(11):1744-1750, 1992.

J. P. Corriou and M. Alamir. A hybrid nonlinear state observer for concentration profiles reconstruction in nonlinear simulated moving bed. Journal of Process Control, 16:345-353, 2006.

J.P. Corriou. Process control - Theory and applications. Springer-Verlag, 2004.

N. Couenne, G. Bornard, J. Chebassier, and D. Humeau. Contrôle et optimisation d'une unité de séparation de xylènes par contre-courant simulé. In SIMO 2002, Toulouse (France), 2002.

G. Erdem, S. Abel, M. Morari, M. Mazotti, M. Morbidelli, and J.H. Lee. Automatic control of simulated moving beds. Ind. Eng. Chem. res., 43:405-421, 2004.

C. E. Garcia and A. M. Morshedi. Quadratic programming solution of dynamic matrix control (QDMC). Chem. Eng. Comm., 46:73-87, 1986.

K. U. Klatt, F. Hanisch, and G. Dünnebier. Model-based control of a simulated moving bed chromatographic process for the separation of fructose and glucose. J. Proc. Cont., 12:203-219, 2002.

E. Kloppenburg and E. D. Gilles. Automatic control of the simulated moving bed process for $\mathrm{C}_{8}$ aromatics separation using asymptotically exact input-output linearization. J. Proc. Cont., (1):41-50, 1999.

M. Mazzotti, G. Storti, and M. Morbidelli. J. Chromatogr. A, 827:161-173, 1998.

S. Natarajan and J. H. Lee. Repetitive model predictive control applied to a simulated moving bed chromatography system. Comp. Chem. Engng., 24:1127-1133, 2000.

R. M. Nicoud. The simulated moving bed: a powerful chromatographic process. $L C-G C$ Int, 5:43-47, 1992. 
K. Schittkowski. NLPQL: A Fortran subroutine solving constrained nonlinear programming problems. Ann. Oper. Res., 5:485-500, 1985.

S. Skogestad, P. Lundstrom, and E.W. Jacobsen. Selecting the best distillation control configuration. AIChE J., 36(5):753-764, 1990.

I.H. Song, S.B. Lee, H.K. Rhee, and M. Mazotti. Chem. Eng. Sci., 61:1973-1986, 2006.

M. Ben Thabet, M. Alamir, M. Bailly, and J. P. Corriou. Nonlinear control of a simulated moving bed. In Conference on Separation Science and Technologies, AIChE 97, Los Angeles, pages 1316-1321, 1997.

A. Toumi and S. Engell. Optimization-based control of a reactive simulated moving bed process for glucose isomerization. Chem. Eng. Sci., 58(18):3777-3792, 2004.

A. Toumi, S. Engell, O. Ludemann-Hombourger, R.M. Nicoud, and M. Bailly. Optimization of simulated moving bed and Varicol processes. Journal of Chromatography A, 1006(1-2):15-31, 2003.

Z. Zhang, M. Mazzotti, and M. Morbidelli. Multiobjective optimization of simulated moving bed and varicol processes using a genetic algorithm. J. Chromatogr. A, 989:95-108, 2003a.

Z. Zhang, M. Mazzotti, and M. Morbidelli. Powerfeed operation of simulated moving bed units: changing flow-rates during the switching interval. Journal of Chromatography A, 1006(1-2):87-99, 2003b. 
Solid $\longrightarrow$

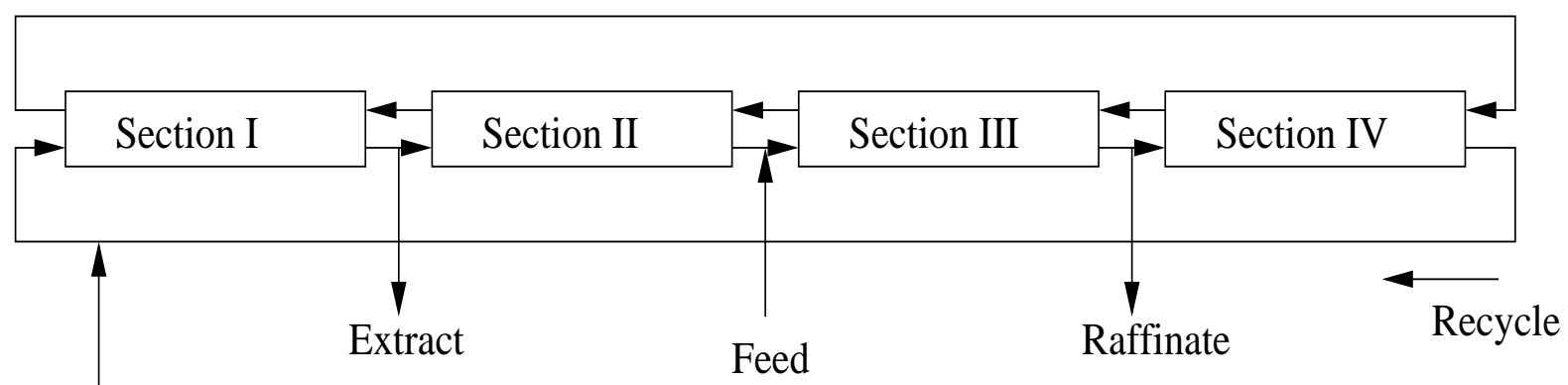

Eluent

Figure 1: True Moving Bed (TMB) separation technology 


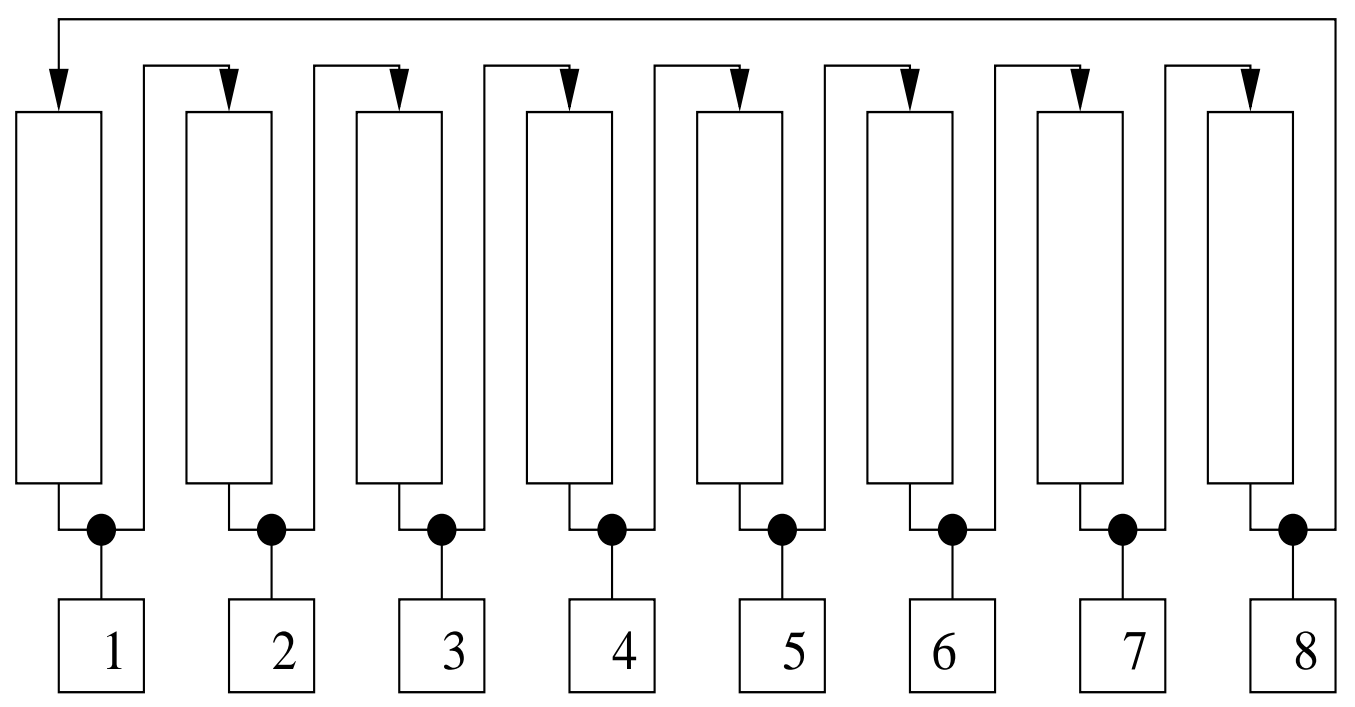

Cycle 0 Eluent Closed Extract Closed Feed Closed Raffinate Closed Cycle 1 Closed Eluent Closed Extract Closed Feed Closed Raffinate Cycle 2 Raffinate Closed Eluent Closed Extract Closed Feed Closed Cycle 3 Closed Raffinate Closed Eluent Closed Extract Closed Feed Cycle 4 Feed Closed Raffinate Closed Eluent Closed Extract Closed Cycle 5 Closed Feed Closed Raffinate Closed Eluent Closed Extract Cycle 6 Extract Closed Feed Closed Raffinate Closed Eluent Closed Cycle 7 Closed Extract Closed Feed Closed Raffinate Closed Eluent Cycle 8(0) Solvent Closed Extract Closed Feed Closed Raffinate Closed

Figure 2: Simulated Moving Bed (SMB) separation technology and its principle of operation with respect to the position of the valves 


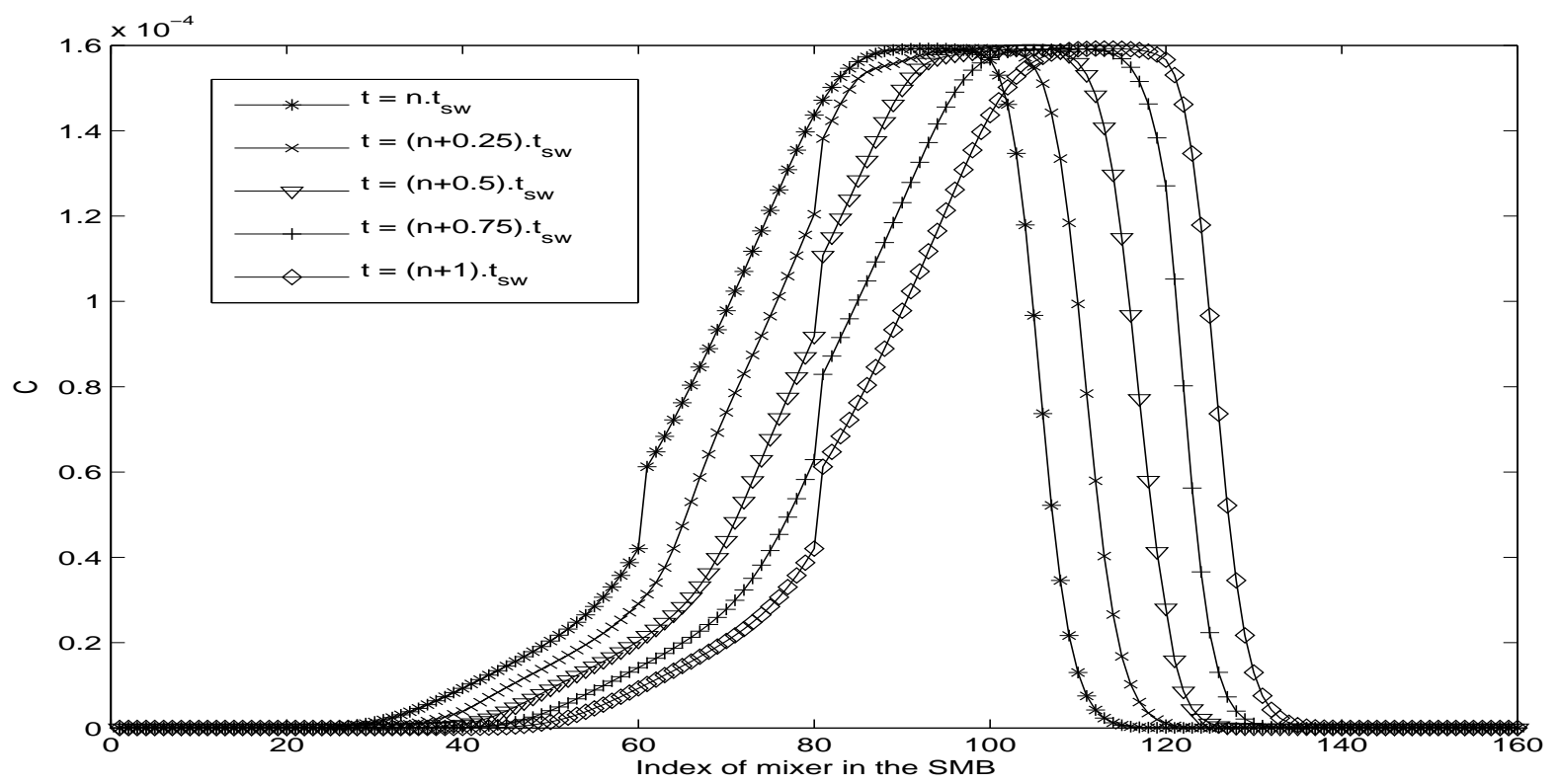

Figure 3: Simulated Moving Bed (SMB) raffinate product concentration. The ports given as index of mixer in the discrete model are: 0: eluent, 40: extract, 80:feed, 120: raffinate. 


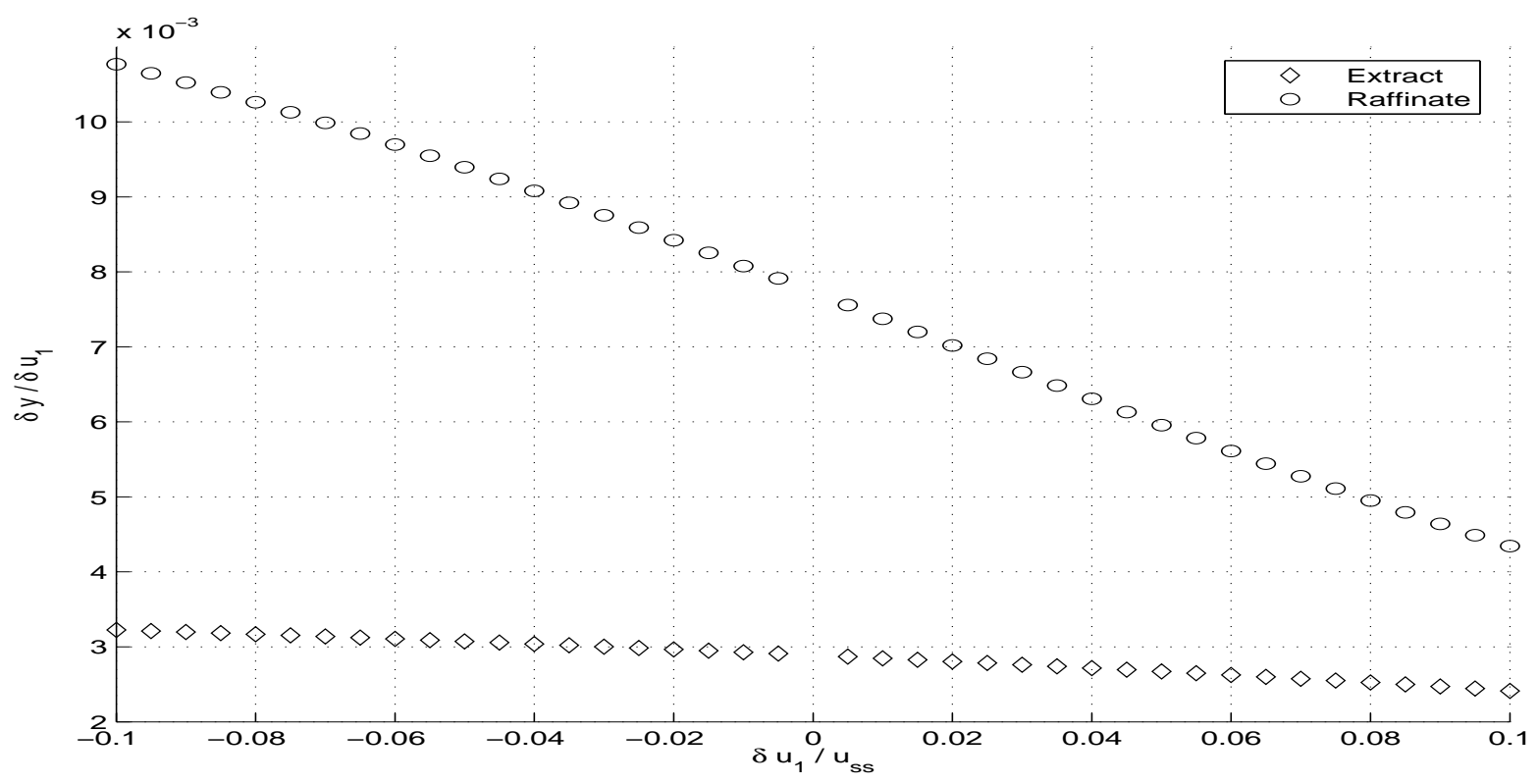

Figure 4: Asymptotic gain for the SMB versus the relative amplitude of the step of the eluent flow rate, in case of flow rate control 


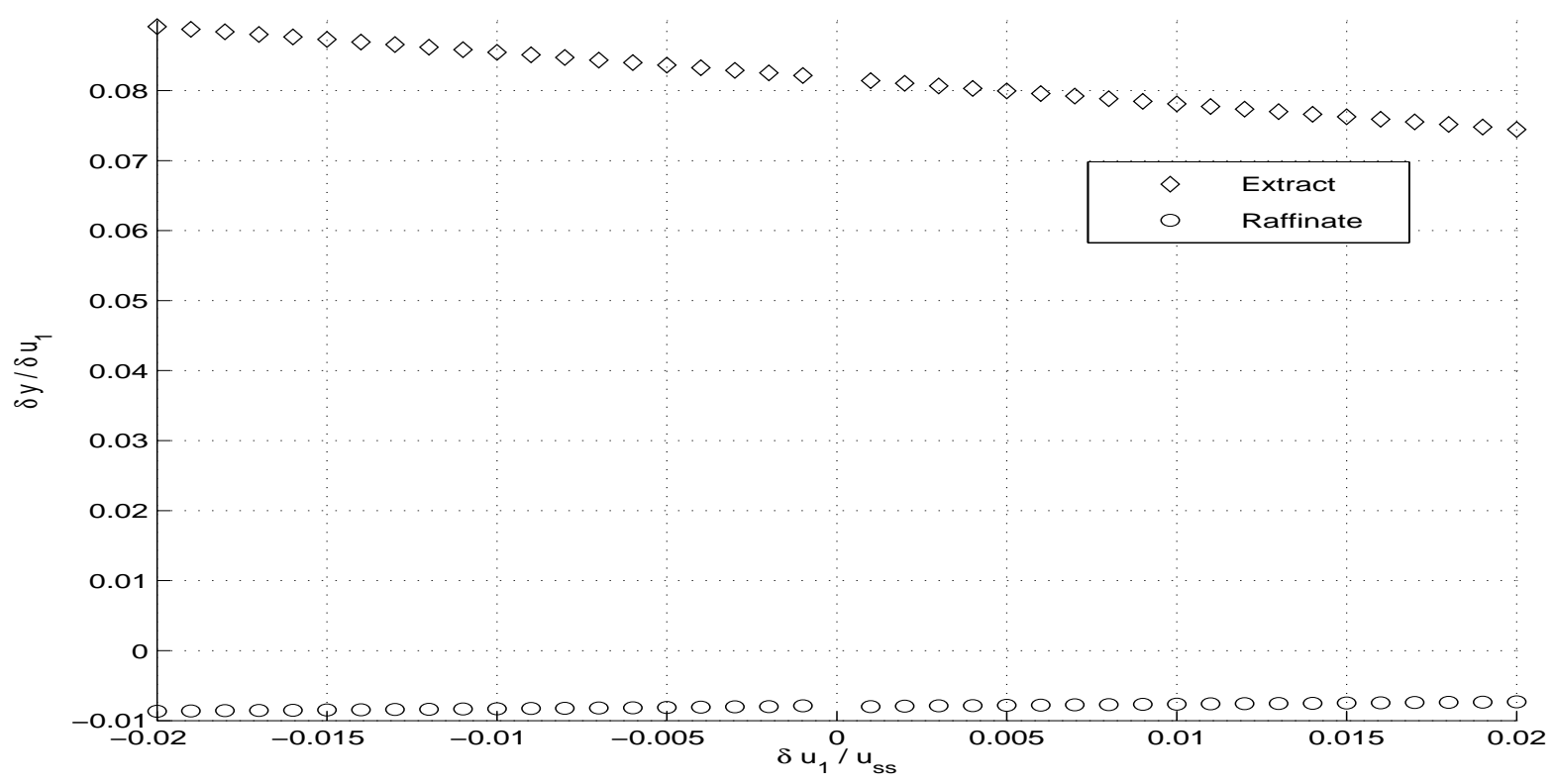

Figure 5: Asymptotic gain for the SMB versus the relative amplitude of the step of the flow rate ratio in section I, in case of ratio control 

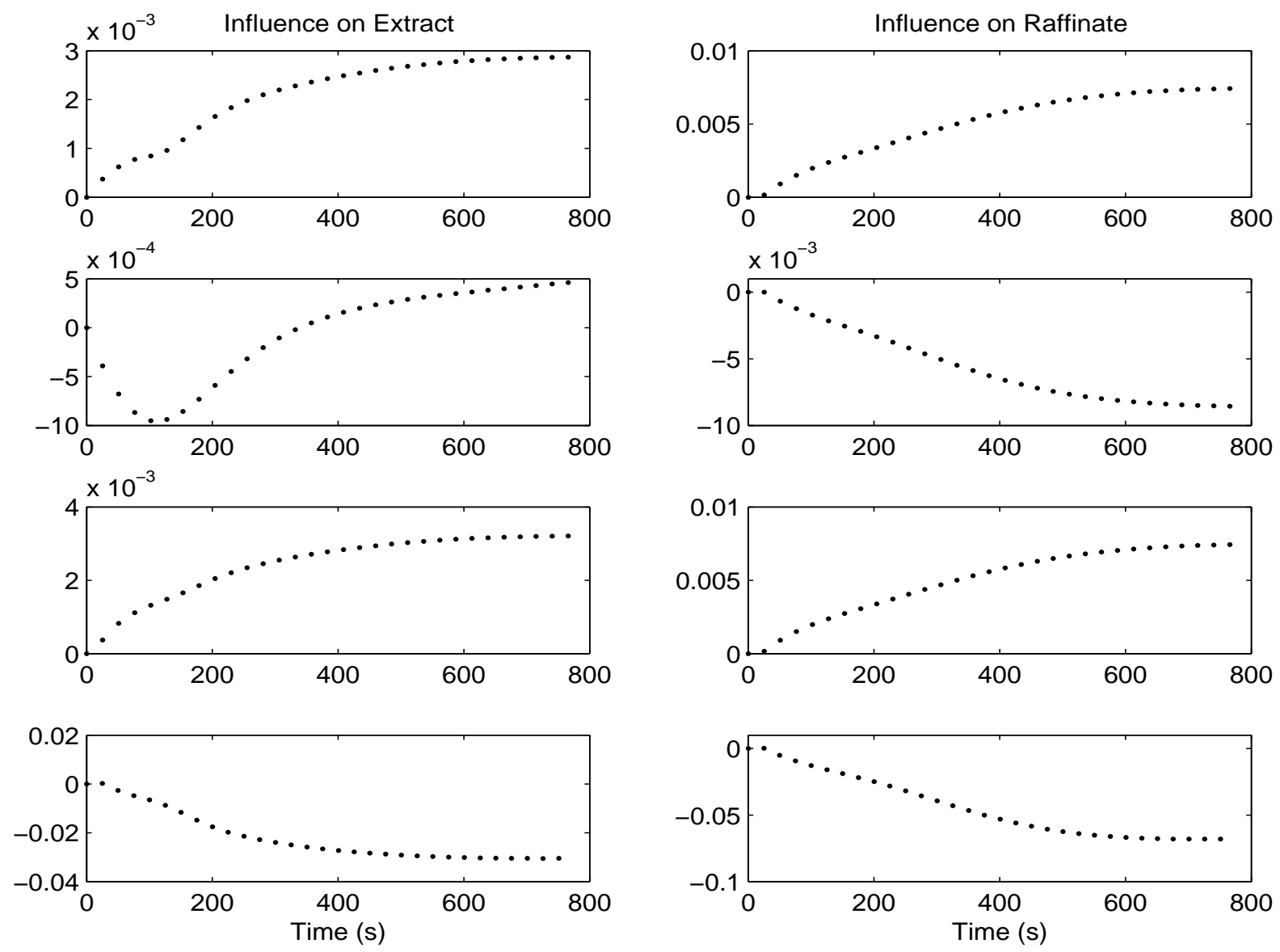

Figure 6: SMB: normalized step responses of the extract and raffinate purities with respect to the flow rates (from top to bottom: eluent, recycle, extract and solid) 

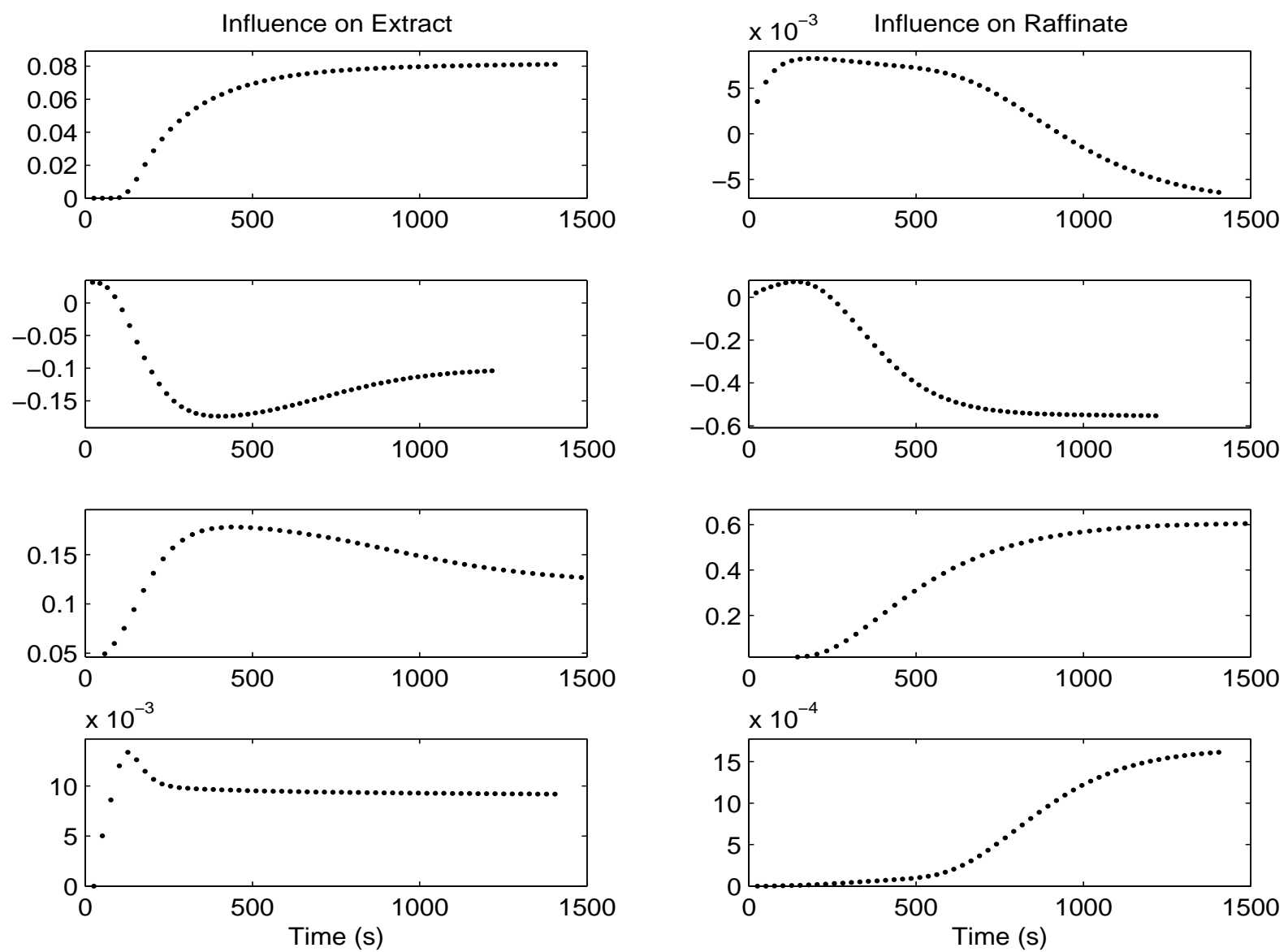

Figure 7: SMB: normalized step responses of the extract and raffinate purities with respect to the flow rates ratios (from top to bottom: ratio in zone 1, zone 2, zone 3, zone 4) 

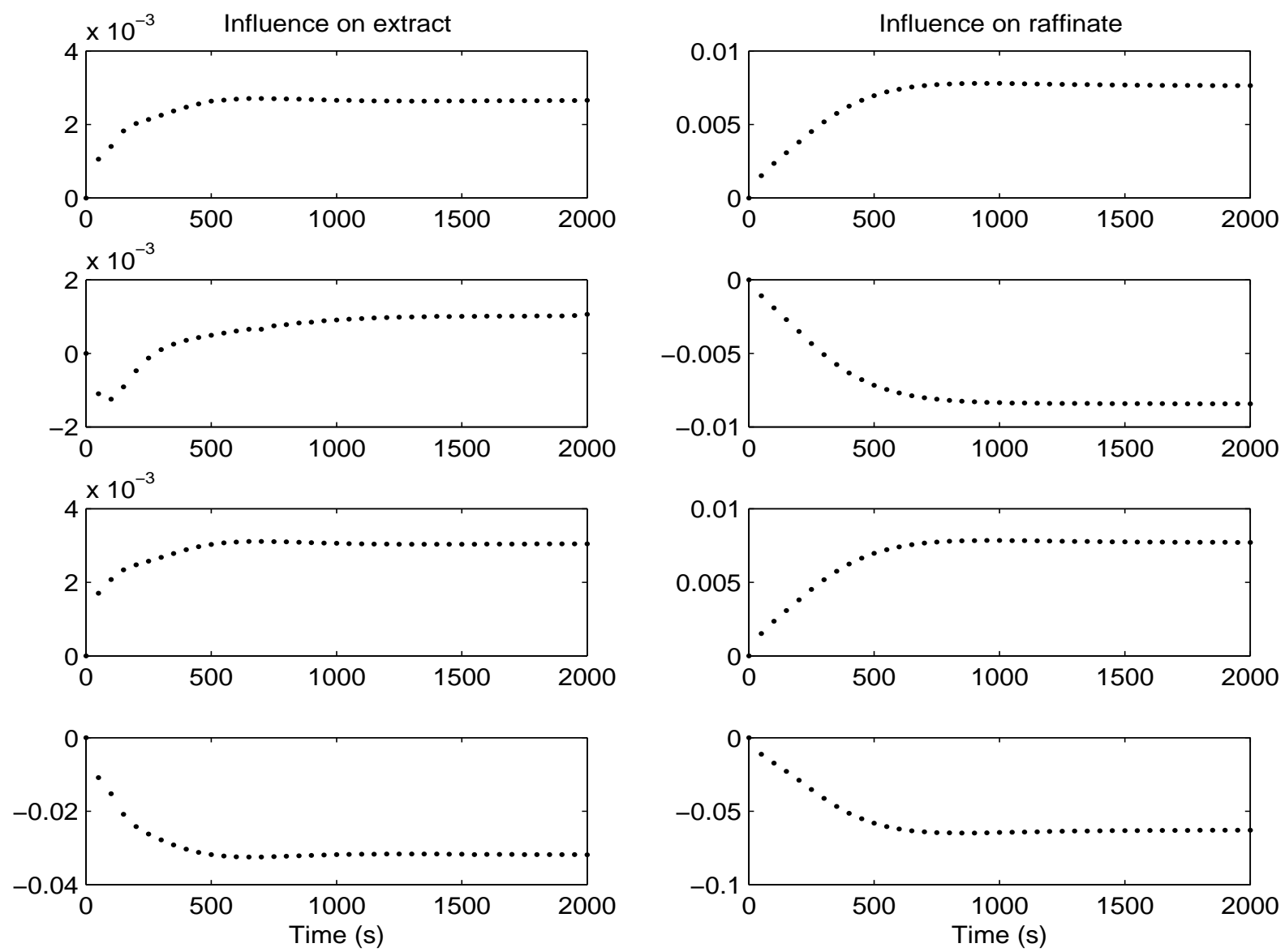

Figure 8: TMB: normalized step responses of the extract and raffinate purities with respect to the flow rates (from top to bottom: eluent, recycle, extract and solid) 

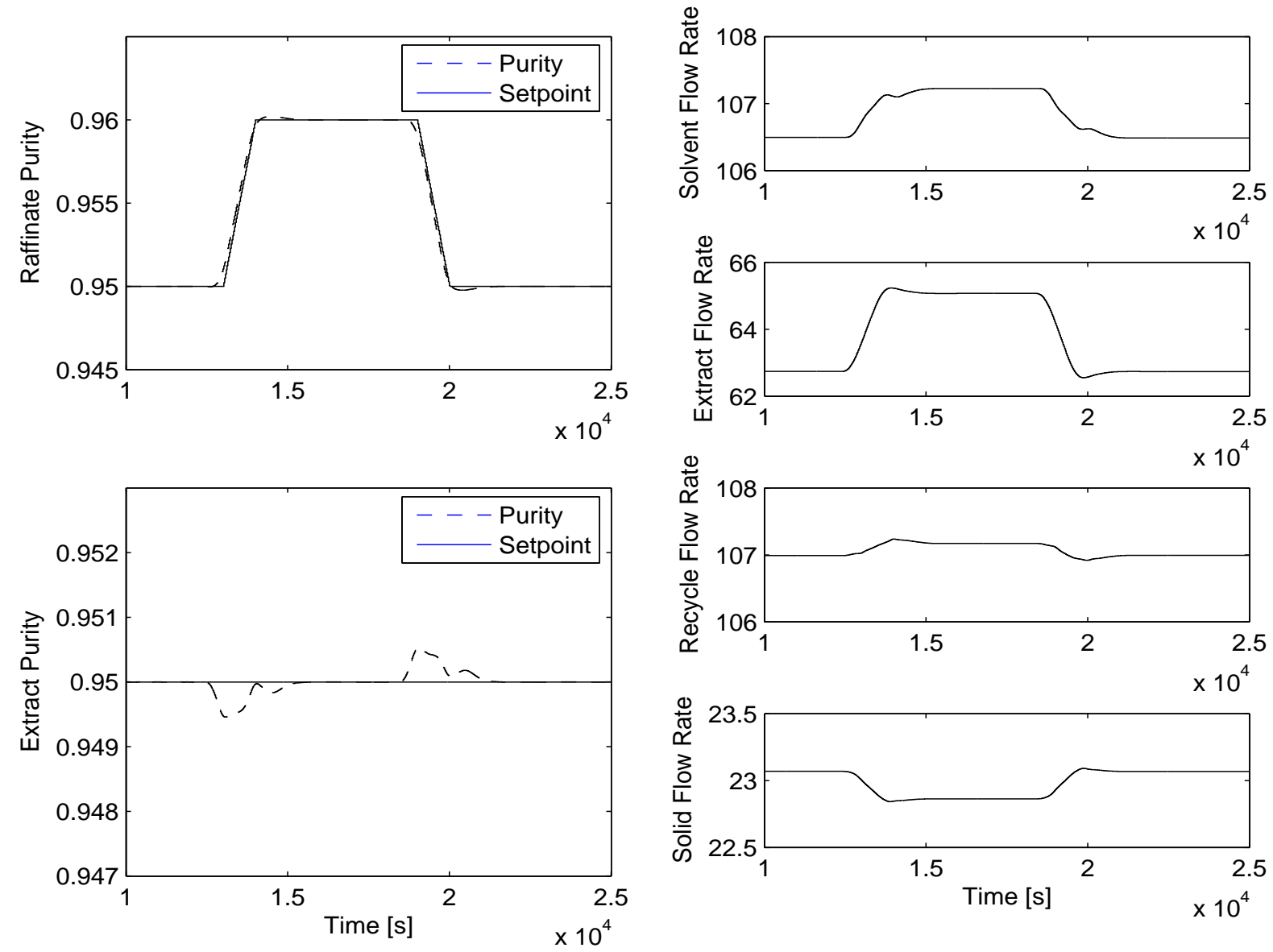

Figure 9: Flow rate control: study of raffinate purity tracking. Left: controlled outputs. Right: manipulated inputs 

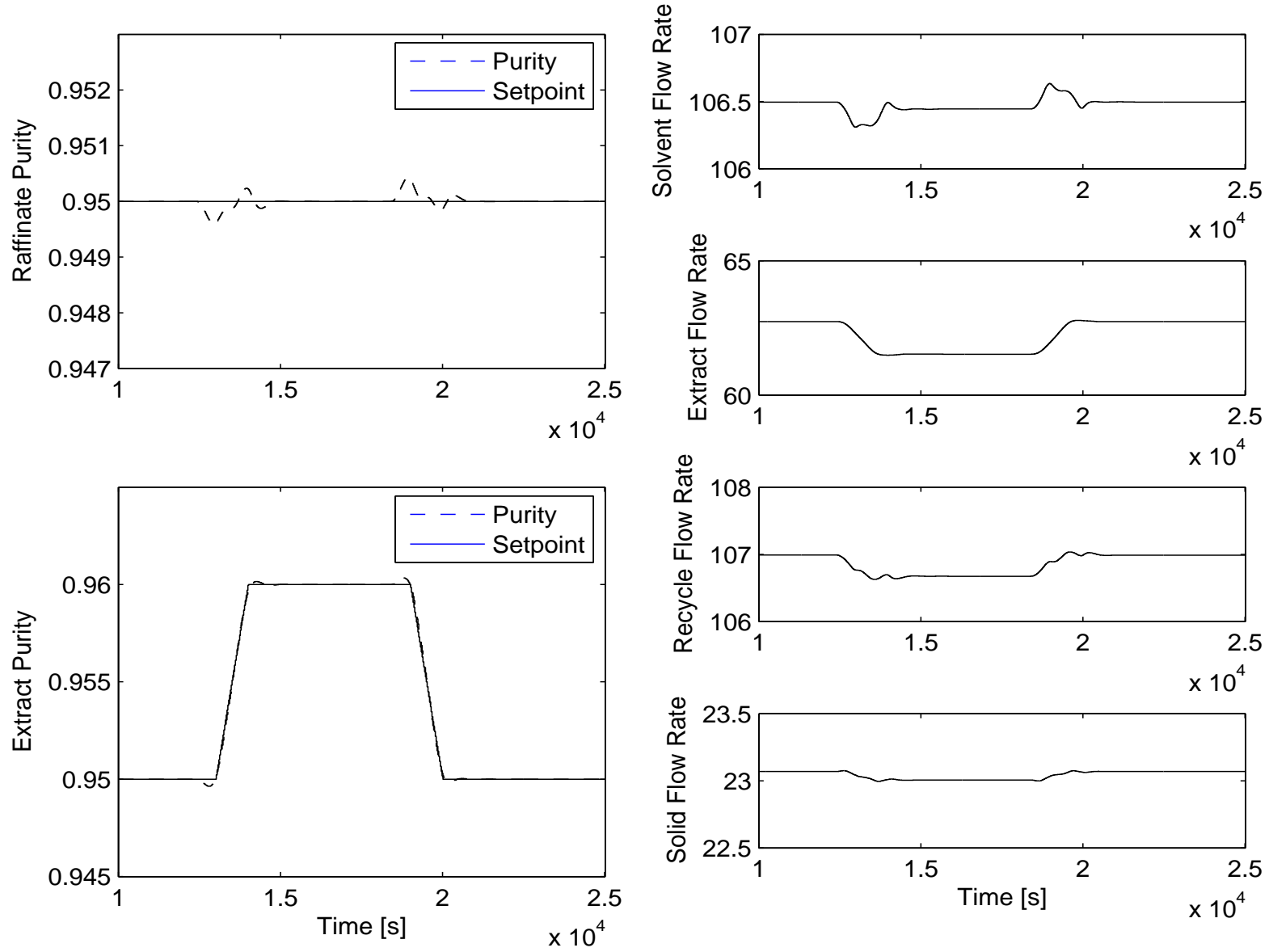

Figure 10: Flow rate control: study of extract purity tracking. Left: controlled outputs. Right: manipulated inputs 

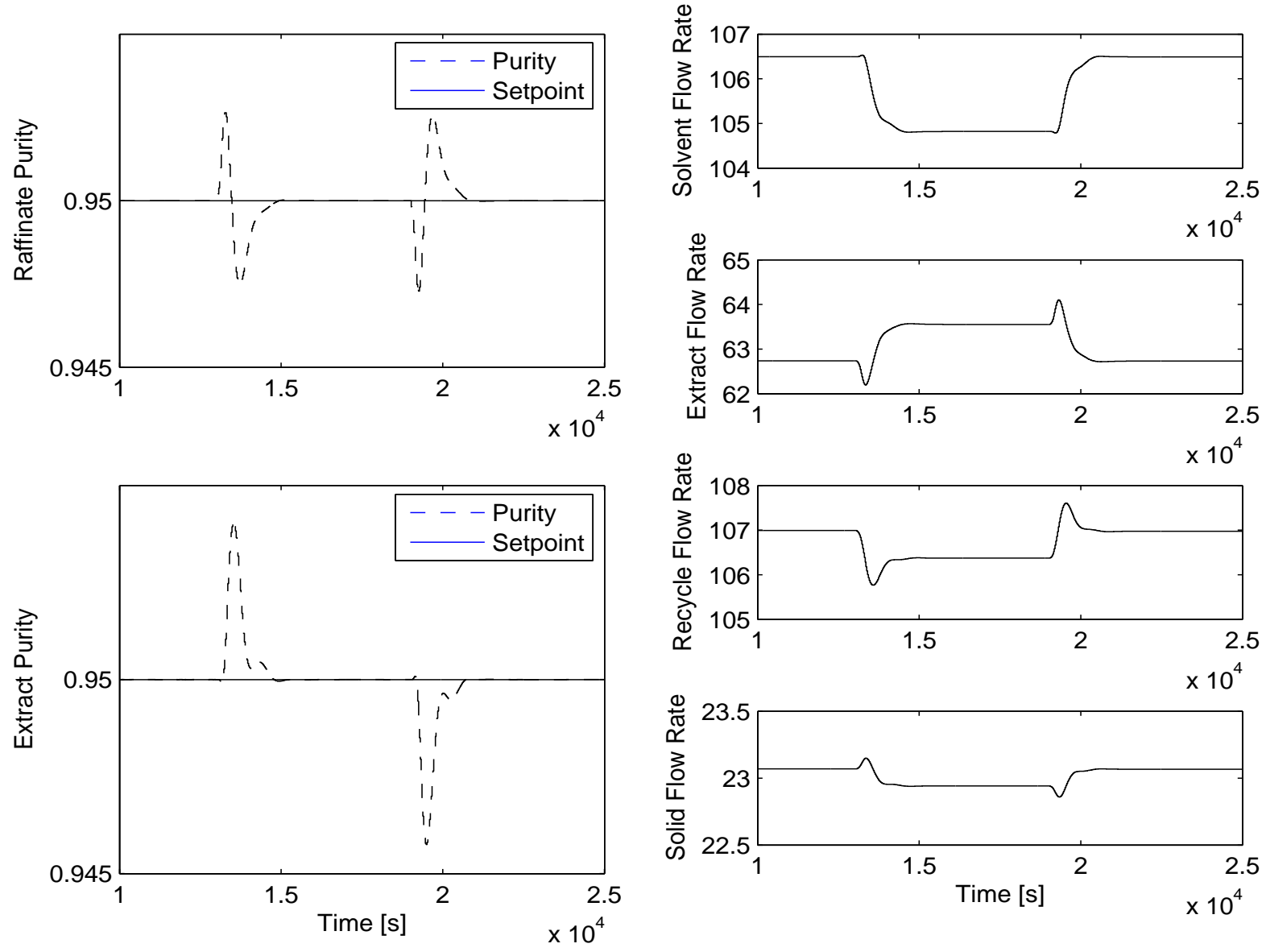

Figure 11: Flow rate control: study of feed flow rate disturbance rejection. Left: controlled outputs. Right: manipulated inputs 

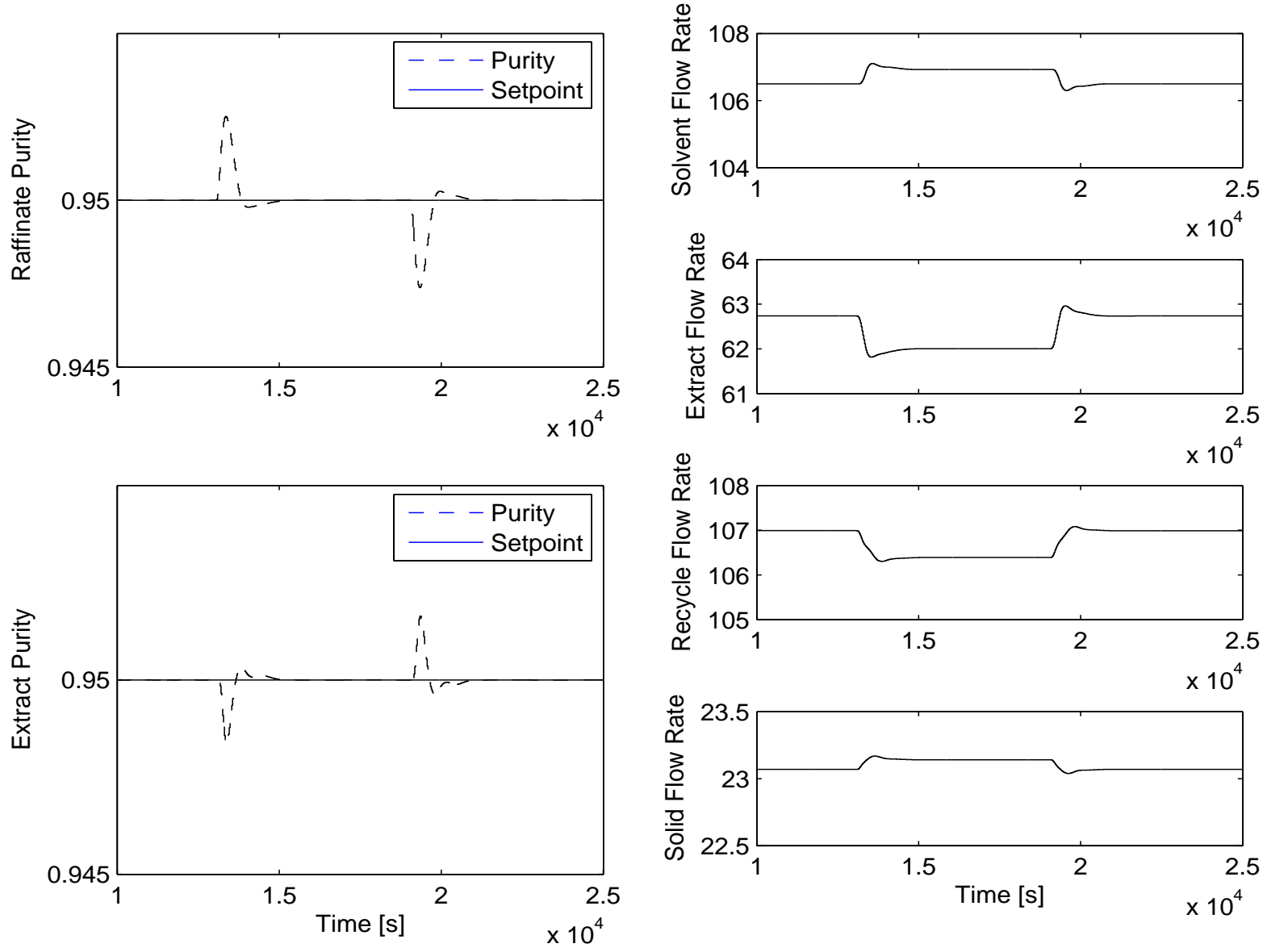

Figure 12: Flow rate control: study of disturbance rejection of A feed concentration. Left: controlled outputs. Right: manipulated inputs 

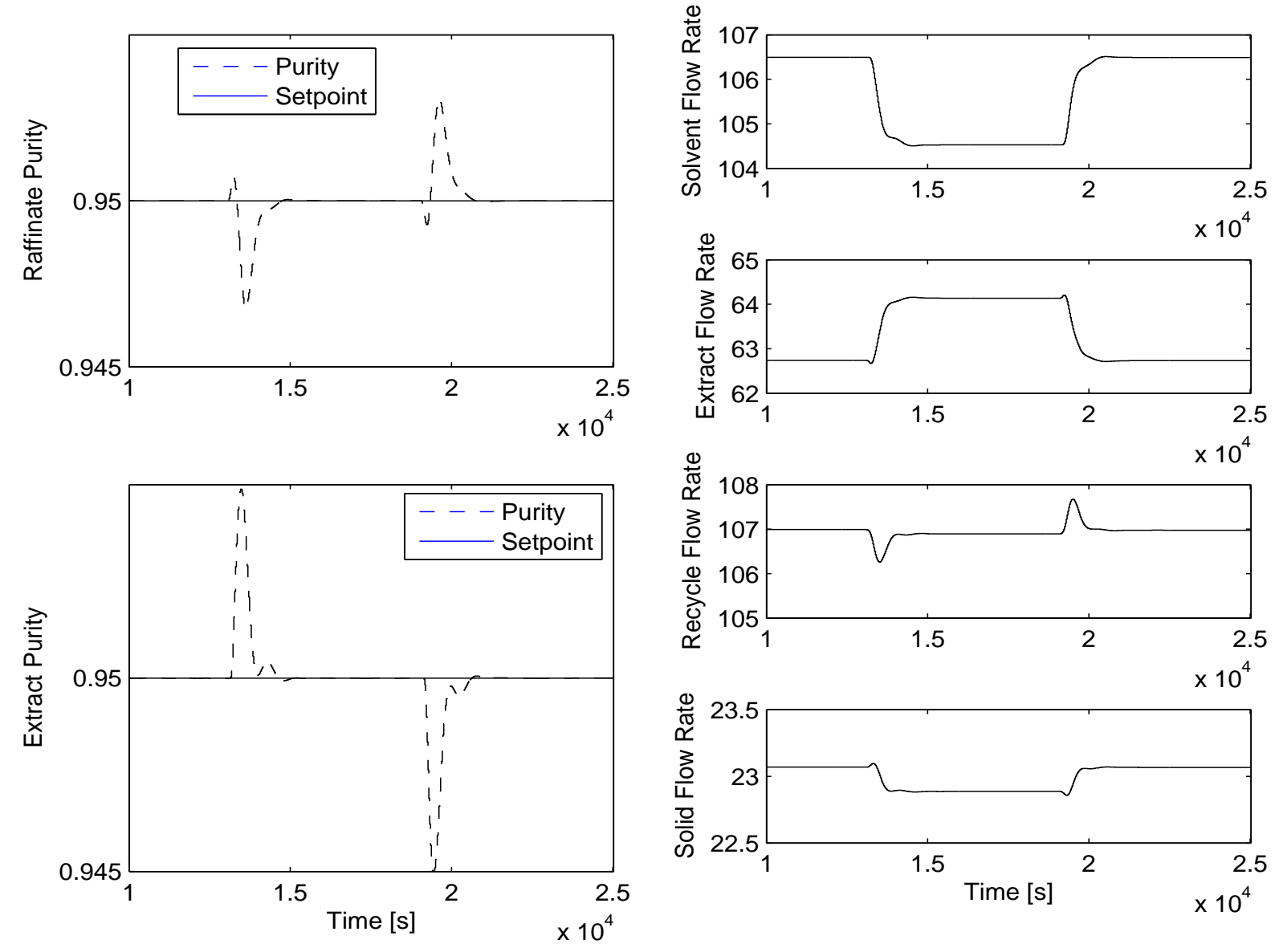

Figure 13: Flow rate control: study of disturbance rejection of B feed concentration. Left: controlled outputs. Right: manipulated inputs 

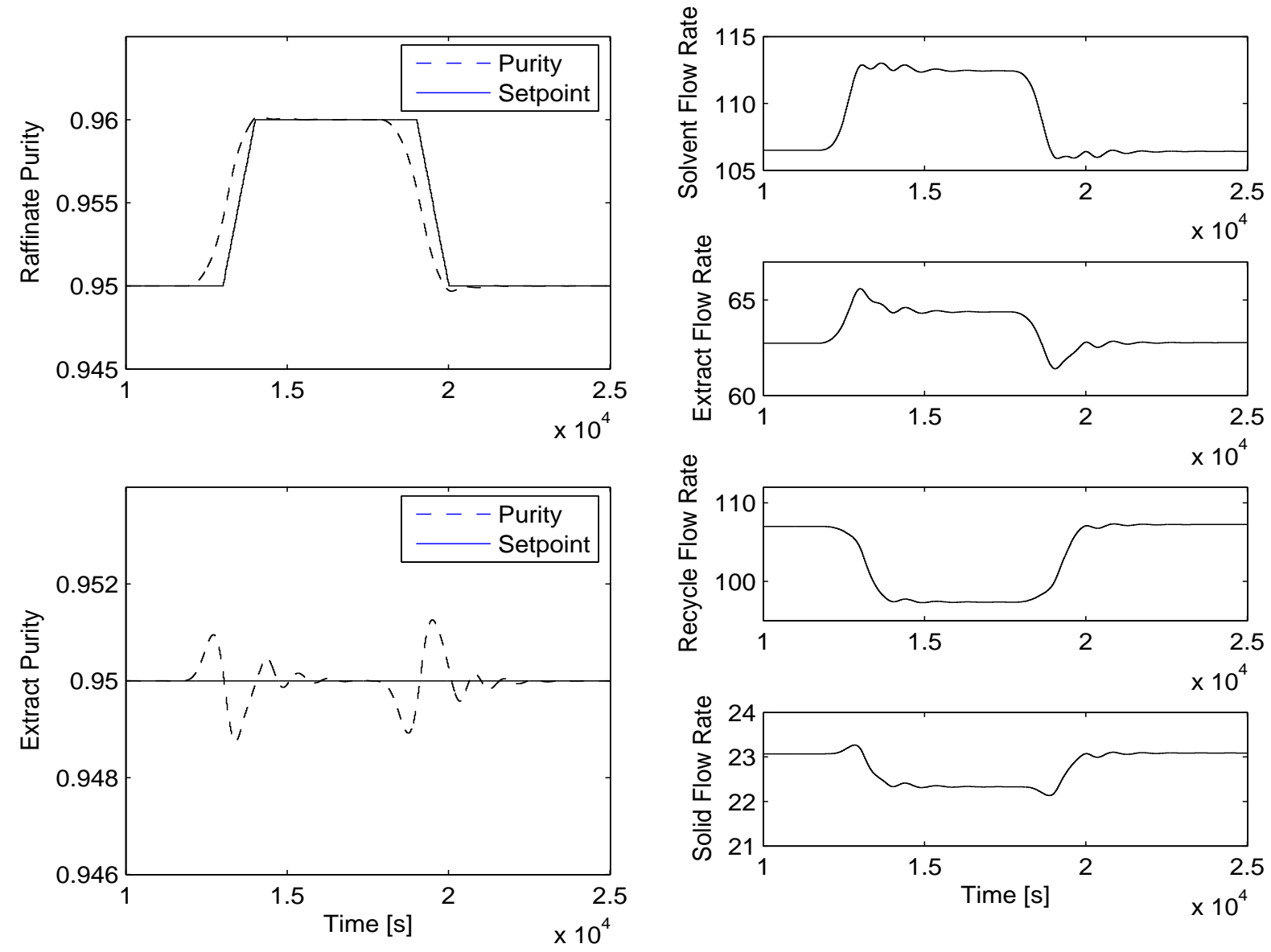

Figure 14: Ratio control: study of raffinate purity tracking. Left: controlled outputs. Right: operating flow rates 

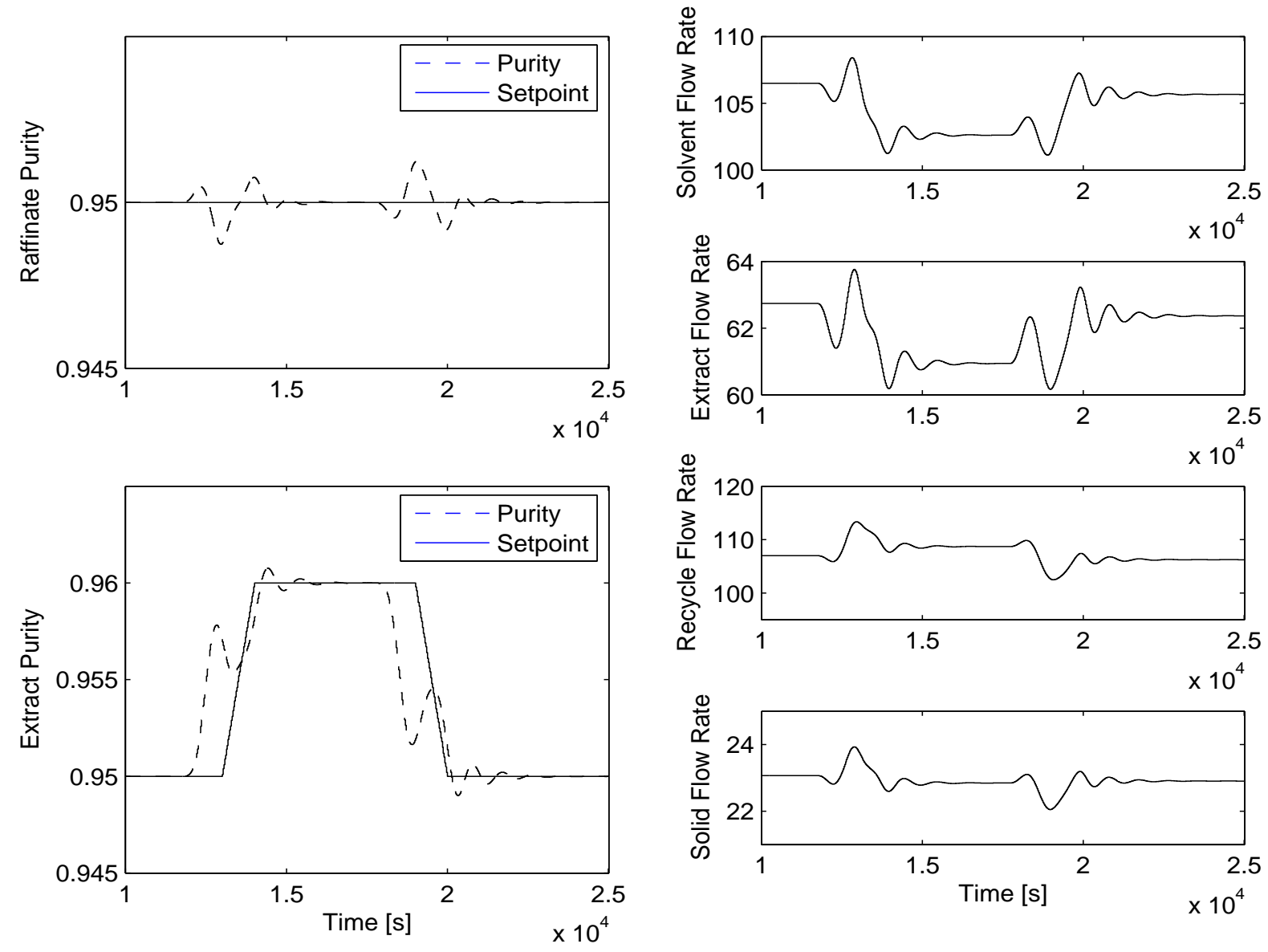

Figure 15: Ratio control: study of extract purity tracking. Left: controlled outputs. Right: operating flow rates 

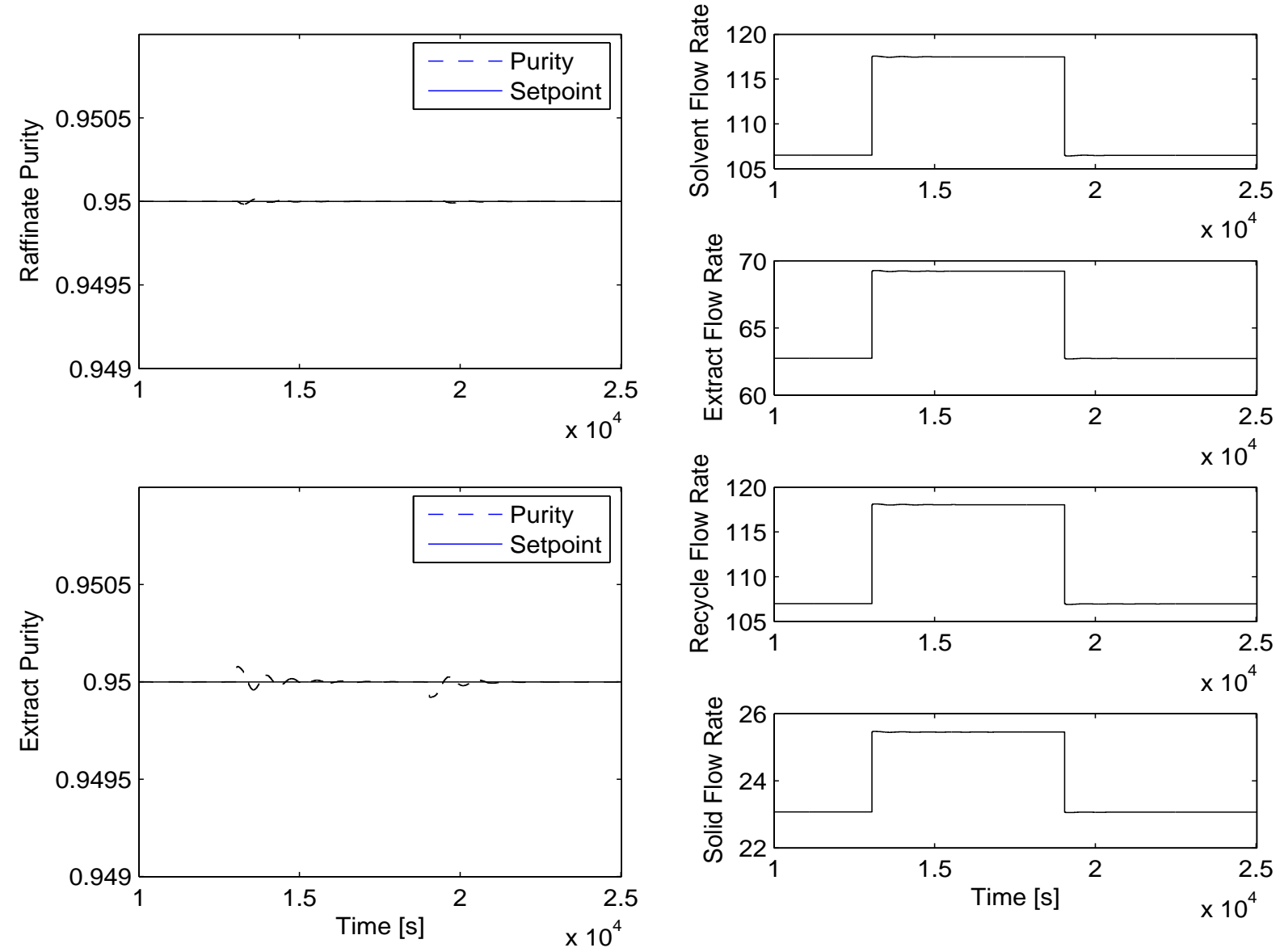

Figure 16: Ratio control: study of feed flow rate disturbance rejection. Left: controlled outputs. Right: operating flow rates 

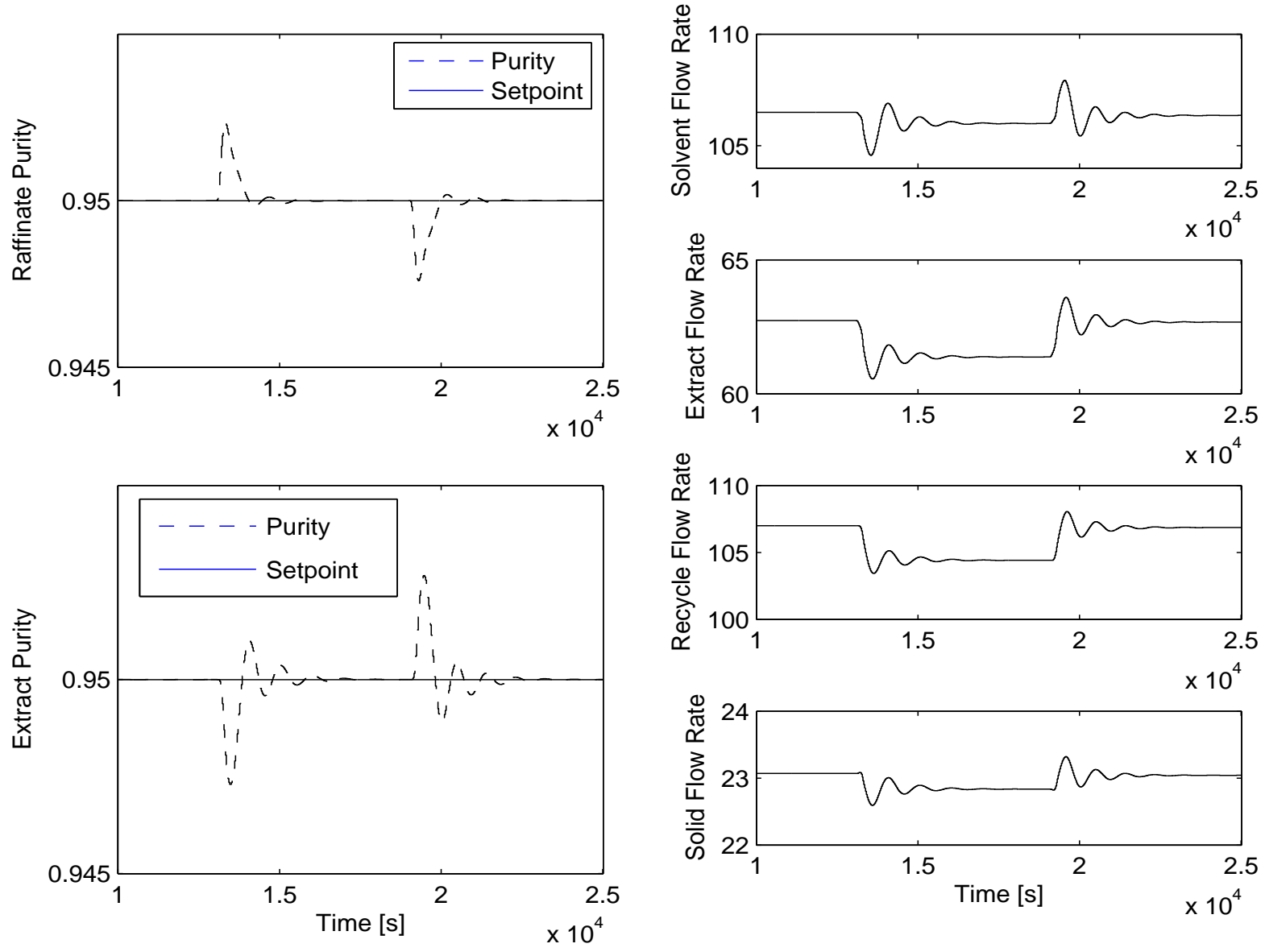

Figure 17: Ratio control: study of disturbance rejection of A feed concentration. Left: controlled outputs. Right: operating flow rates 

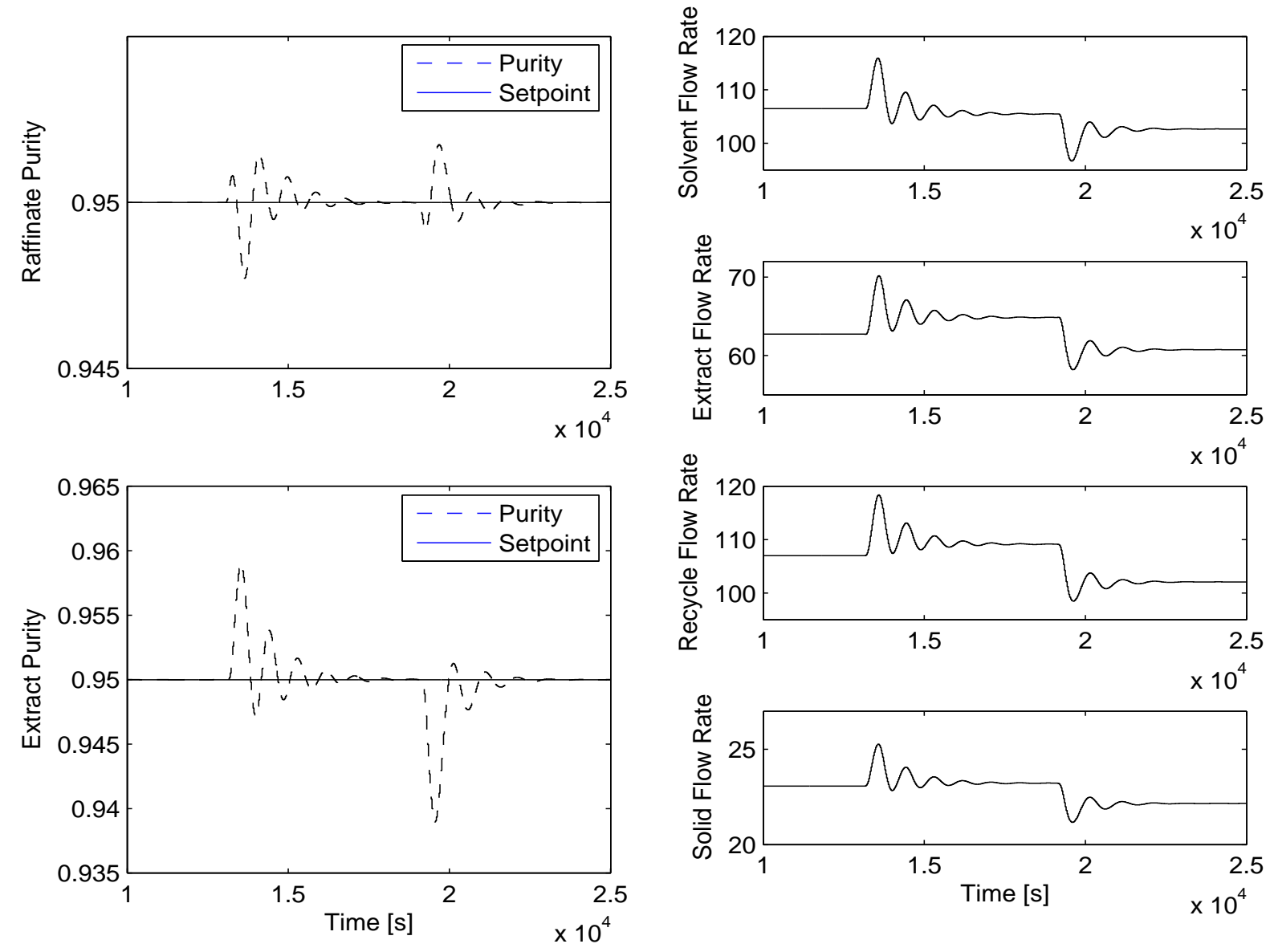

Figure 18: Ratio control: study of disturbance rejection of B feed concentration. Left: controlled outputs. Right: operating flow rates 

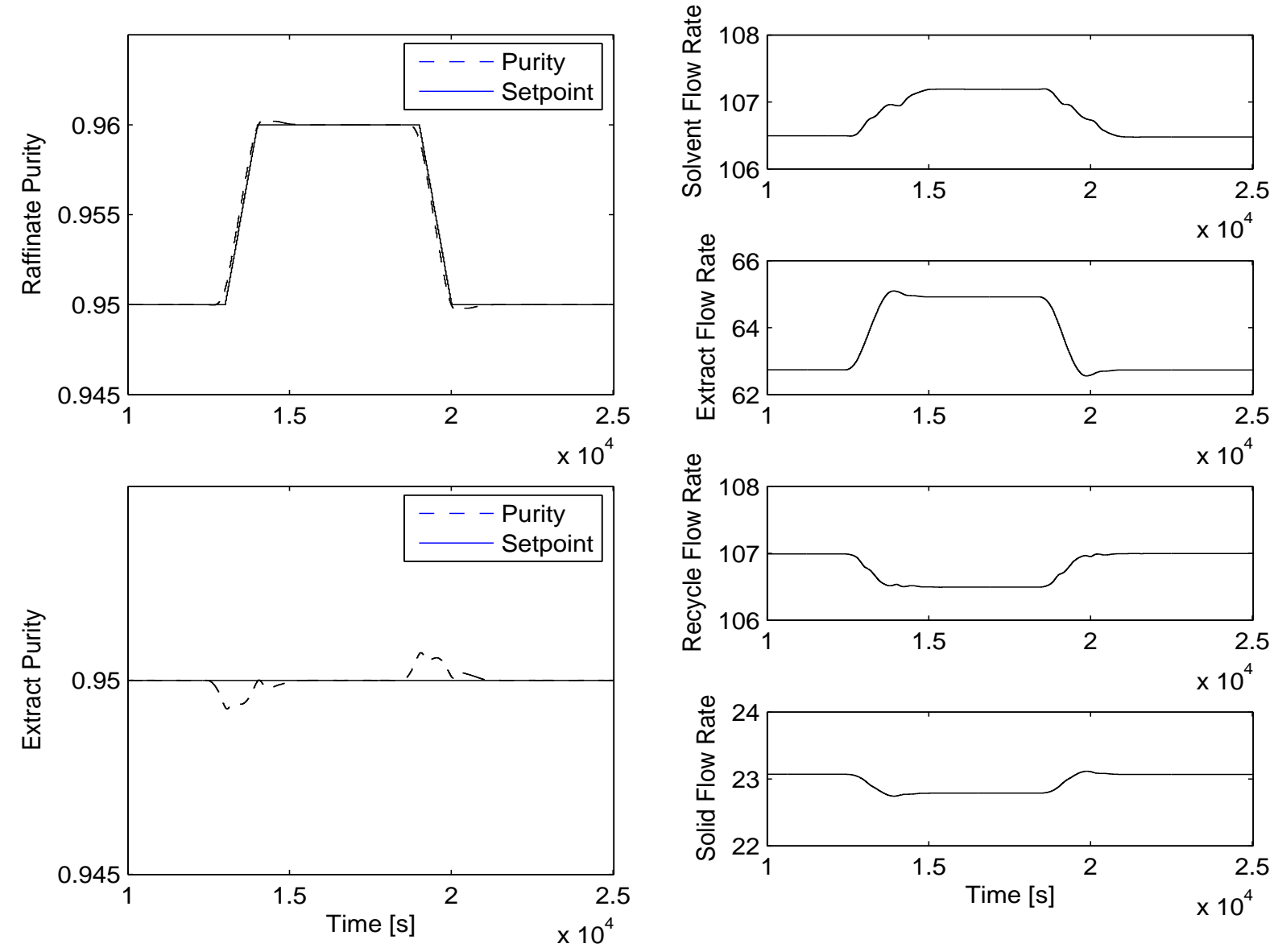

Figure 19: Hybrid control: study of raffinate purity tracking. Left: controlled outputs. Right: operating flow rates 

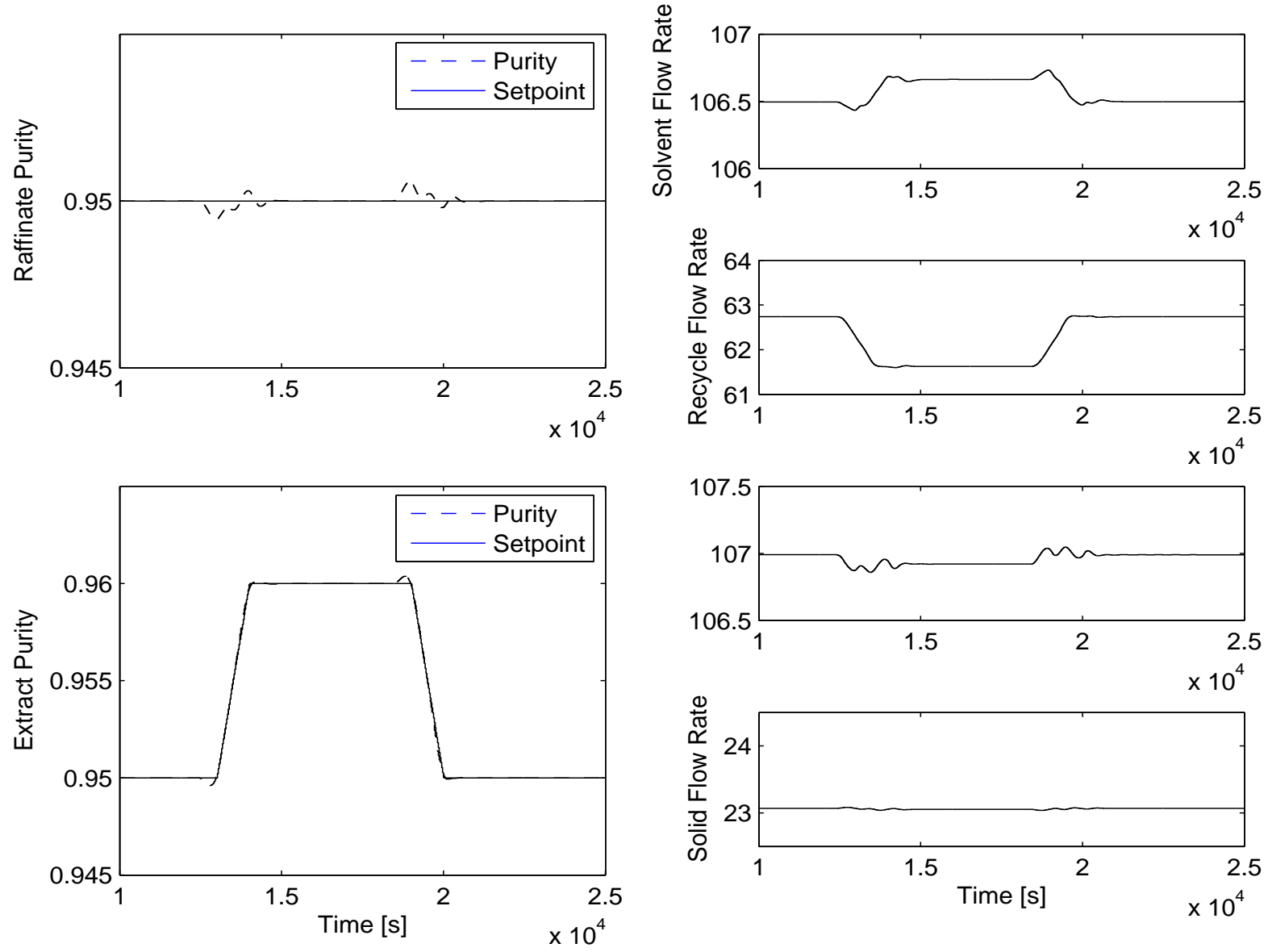

Figure 20: Hybrid control: study of extract purity tracking. Left: controlled outputs. Right: operating flow rates 

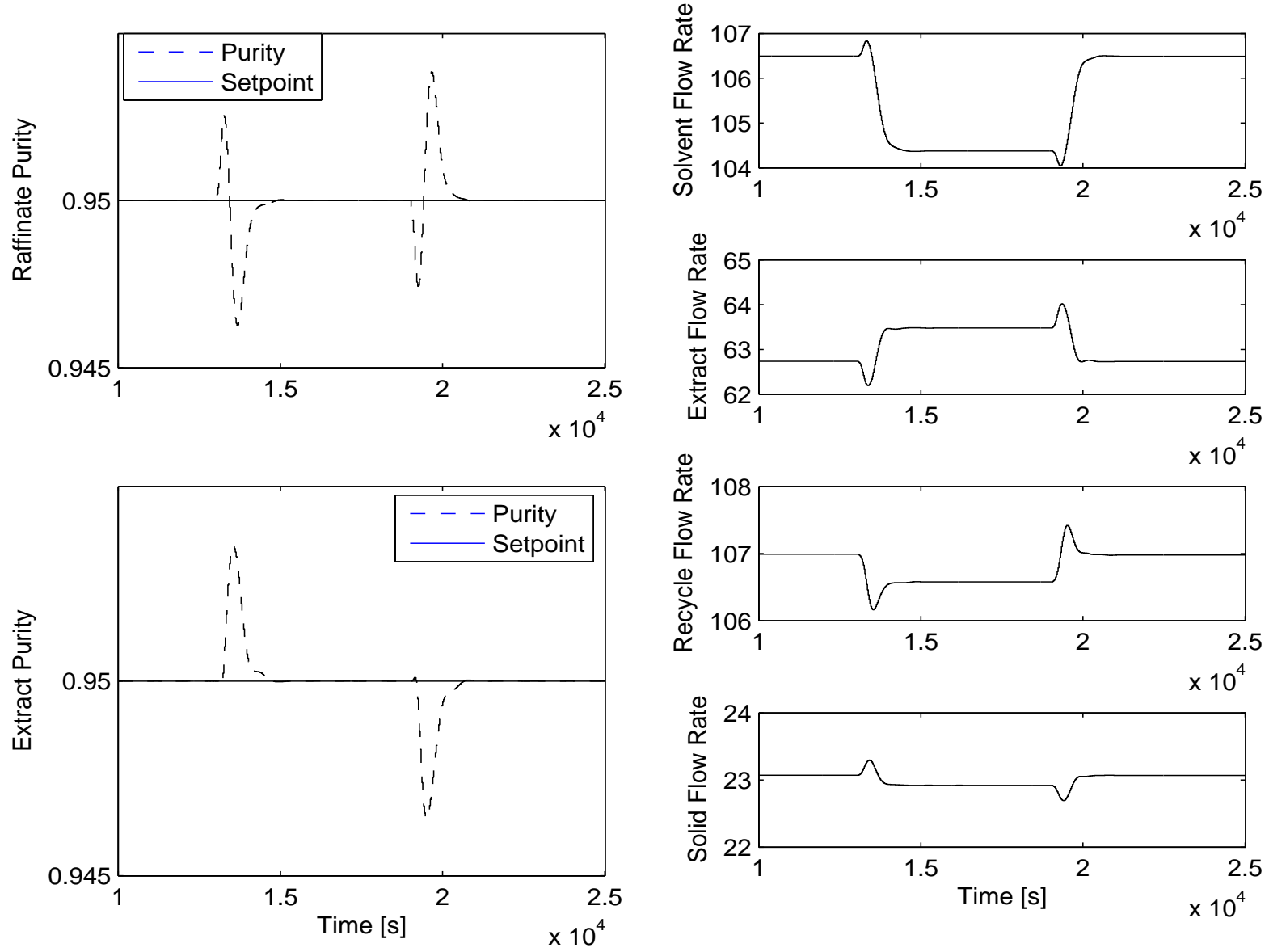

Figure 21: Hybrid control: study of feed flow rate disturbance rejection. Left: controlled outputs. Right: operating flow rates 

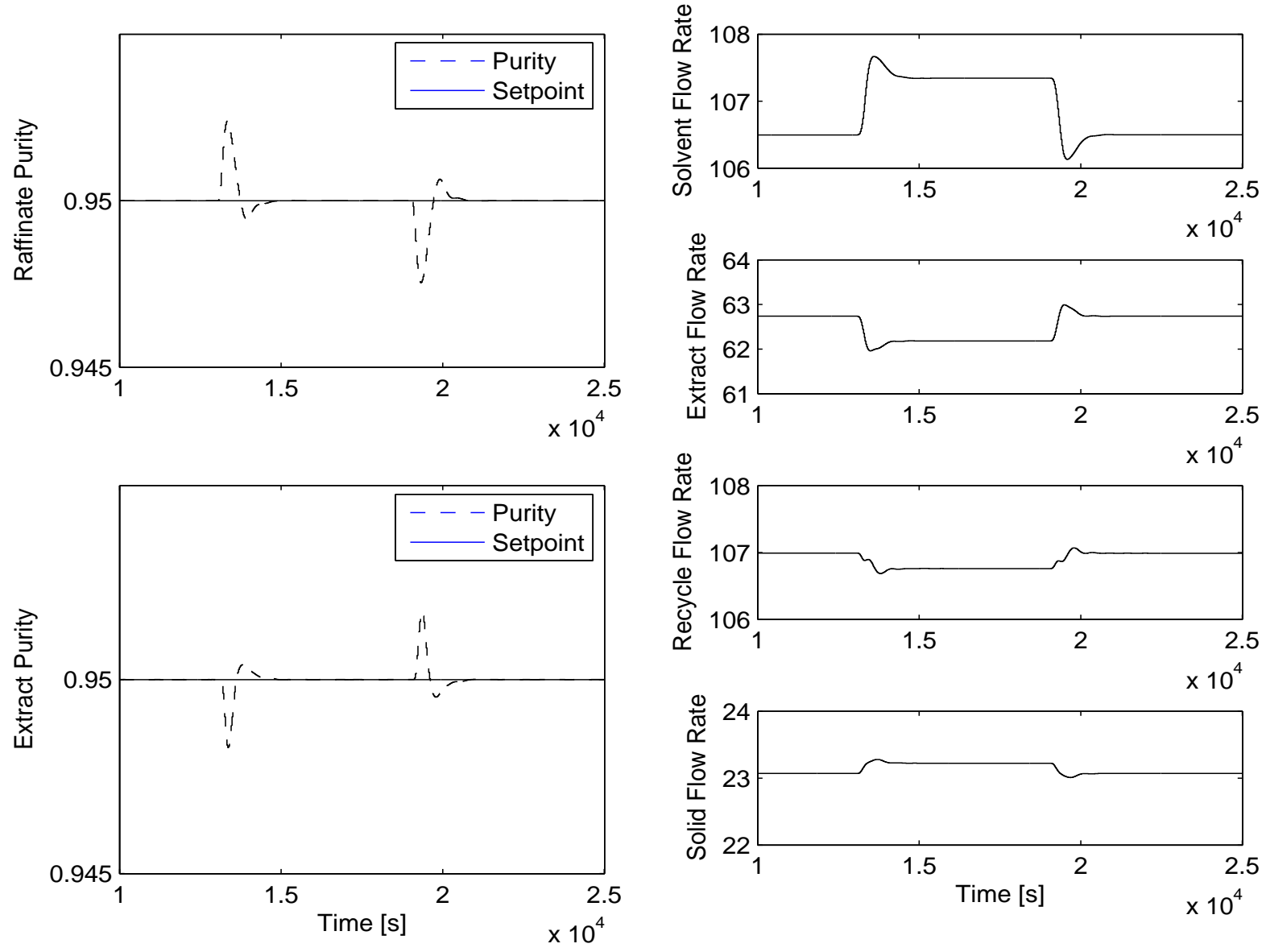

Figure 22: Hybrid control: study of disturbance rejection of A feed concentration. Left: controlled outputs. Right: operating flow rates 

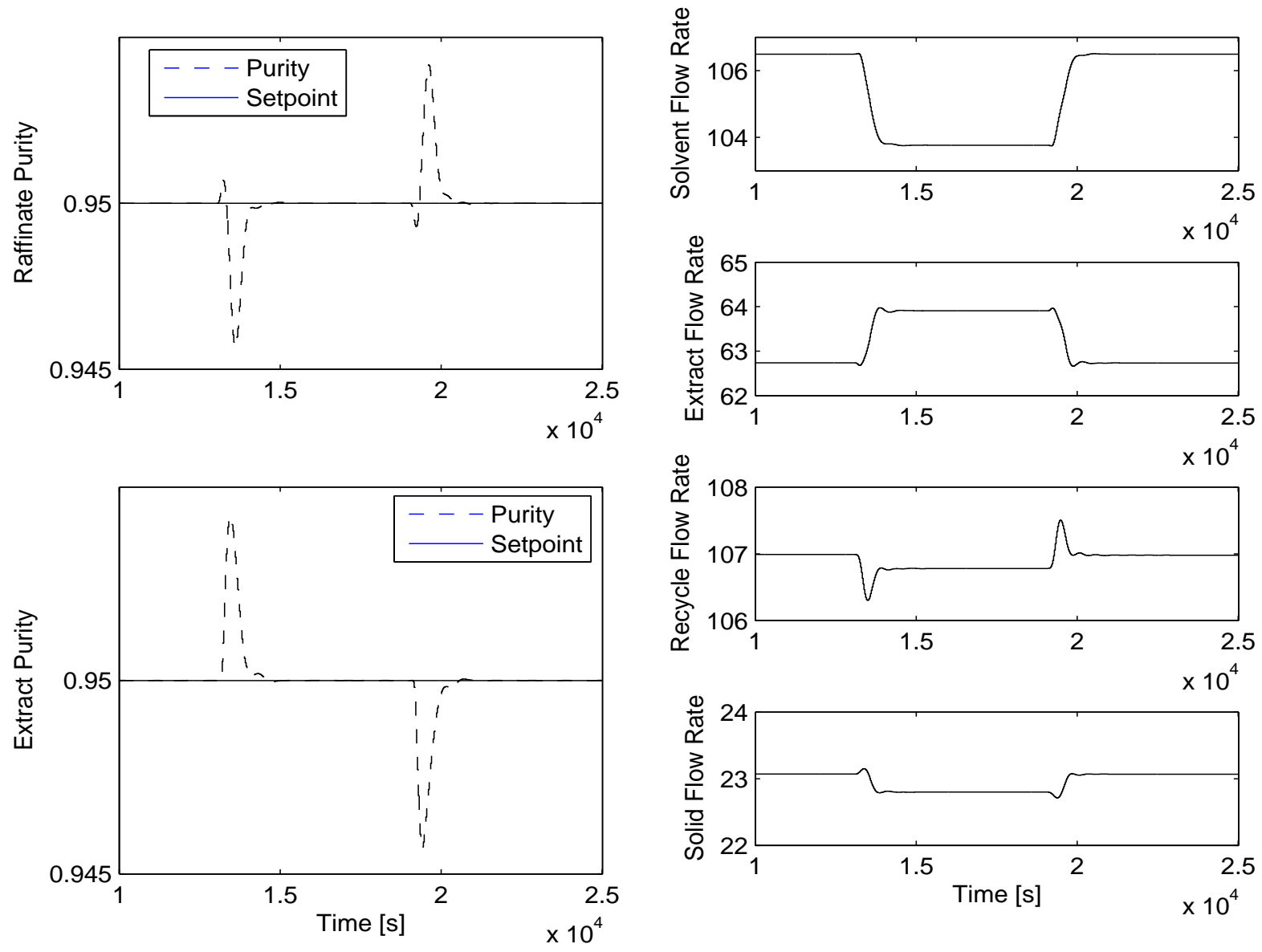

Figure 23: Hybrid control: study of disturbance rejection of B feed concentration. Left: controlled outputs. Right: operating flow rates 